\title{
Proposta de um Indicador Socioeconômico para os Alunos das Escolas Públicas dos Municípios Brasileiros
}

\author{
Thiago Alves ${ }^{1}$ \\ Maria Aparecida Gouvêa ${ }^{2}$ \\ Adriana Backx Noronha Viana ${ }^{2}$
}

${ }^{1}$ Faculdade de Administração, Economia e Contabilidade da Universidade Federal de Goiás (FACE/UFG), Goiânia, Brasil

${ }^{2}$ Faculdade de Economia, Administração e Contabilidade (FEA), da Universidade de São

Paulo (USP), São Paulo, Brasil

\section{INTRODUÇÃO}

\begin{abstract}
o longo do século $X X$ chegou-se a um consenso sobre a importânA cia da escolarização da população diante das inúmeras evidências de forte associação entre educação e desenvolvimento econômico e das externalidades positivas geradas pela educação no campo político e social, tais como o fortalecimento da democracia, modernização da sociedade, melhoria dos indicadores de saúde pública, alívio da pobreza, redução da desigualdade social, convívio social pacífico etc. (Schultz, 1973; Blaug, 1992; Tedesco, 2002; Cury, 2008). Compreendeu-se também que os resultados da educação no âmbito da sociedade eram indiretos e decorrentes dos retornos do processo educacional aos indivíduos por meio do desenvolvimento de: (i) habilidades em leitura, escrita, matemática, história e ciência; (ii) pensamento crítico e capacidade de resolver problemas; (iii) habilidades sociais e ética no trabalho; (iv) cidadania e responsabilidade social; (v) fundamentos para saúde física; (vi) habilidades emocionais (tais como autoconfiança, respeito pelos outros, capacidade de resistir a pressões para ter comportamentos pessoais irresponsáveis); (vii) apreço pelas artes e literatura; além de (viii) habilidades para o mundo do trabalho (Rothstein e Jacobsen, 2008). Assim, diante dos resultados esperados pela sociedade e pelos indivíduos e do avanço das conquistas no campo dos direitos sociais, a oferta da educação em muitas nações passou a ser um dever do Estado (Bobbio, 1992; Cury, 2008).
\end{abstract}

DADOS - Revista de Ciências Sociais, Rio de Janeiro, vol. 57, no-1, 2014, pp. 129 a 166. 
Contudo, o que se observa, sobretudo nos países em desenvolvimento, é uma estratificação das oportunidades educacionais decorrente de fatores (histórico-culturais, econômicos, políticos e sociais) que, interrelacionados, impactam a demanda educacional das famílias e a oferta do ensino por parte do Estado e geram grande disparidade da apropriação dos resultados educacionais entre os grupos sociais. Assim, apesar de a educação ser um bem público que deveria ser provido de forma a possibilitar que todos os indivíduos usufruam dos seus benefícios sem diferenciações, o que se tem observado é a desigualdade educacional como resultado da educação concebida como privilégio de classes e orientada pela condição econômica e social não escolhida dos indivíduos (Coleman et al., 1966; Rutter et al., 1979; White, 1982; Barros et al., 2001; Buchmann e Hannum, 2001; Sirin, 2005).

Este fenômeno, que é mais intenso nos países em processo de desenvolvimento mais iminente, onde a educação é um fator determinante para a manutenção da grande distância que separa os estratos sociais (Buchmann e Hannum, 2001; Barros et al., 2001), tem sido persistente também em sociedades mais igualitárias dos países desenvolvidos, como nos Estados Unidos (Reardon e Robinson, 2008).

No Brasil, embora o direito à educação e o dever do Estado quanto a sua provisão estejam grafados na legislação vigente ${ }^{1}$, o desafio de superar a exclusão educacional dos indivíduos oriundos das camadas mais pobres da sociedade é antigo e remonta à época da independência (Almeida, 1989). Todavia, apesar dos avanços ocorridos desde aquela época, principalmente a partir da década de 1970 no que se refere ao acesso e à recente busca pela qualidade do ensino (Oliveira, 2007), ficaram as marcas sociais da longa convivência (ainda não resolvida) com um sistema educacional altamente seletivo e excludente socioeconomicamente sob a forma da intensa desigualdade entre a minoria rica e a maioria pobre e dos inúmeros problemas sociais que retroalimentam o ciclo de exclusão educacional dos mais desfavorecidos (Cury, 2008).

Diante deste contexto e da necessidade de combater a desigualdade educacional como forma de amenizar as disparidades sociais, o objetivo deste artigo é (a) propor um indicador para descrever a situação socioeconômica dos alunos das escolas públicas de educação básica nos municípios brasileiros e (b) evidenciar as diferenças entre os municípios (consequentemente, entre estados e regiões).

O Indicador Socioeconômico Estudantil dos Municípios (ISE-M) foi assim denominado, pois, diferente dos demais indicadores sociais que 
buscam retratar a realidade de toda a população, foi calculado com base nos dados relativos aos recursos econômicos (bens e serviços disponíveis nos domicílios) e do contexto socioeducacional das famílias (nível de escolaridade dos pais) dos alunos do ensino fundamental das escolas públicas. Para isso, foram utilizados os dados da Prova Brasil realizada em $2011^{2}$ (edição mais recente disponível) pelo Instituto Nacional de Estudos e Pesquisas Educacionais Anísio Teixeira (Inep) e pelo Ministério da Educação (MEC), mais especificamente aqueles levantados por meio do questionário socioeconômico, agregados por município.

A escolha do nível municipal para apresentação do indicador (e não por aluno ou escola) deve-se à necessidade de descrever a realidade educacional das redes de ensino, ou seja, nos níveis dos entes federativos em que são definidas as políticas públicas ${ }^{3}$. Deve-se também ao papel que os municípios brasileiros assumiram após a Constituição de 1988 para o atendimento das demandas sociais locais (Souza, 2005), demandas estas que foram aumentadas em decorrência dos programas de descentralização das políticas sociais que ocorreram a partir da década de 1990 (Arretche, 2000), não obstante as controvérsias em relação à autonomia, ao efetivo empoderamento das comunidades locais no processo decisório sobre políticas públicas e à capacidade técnica e tributária dos governos municipais (Pacheco, 1999). De qualquer forma, esta escolha não está isenta do risco de encobrir as grandes disparidades dentro de cada localidade e de comparar realidades educacionais muito distintas. Contudo, em que pesem as questões do federalismo brasileiro, as diferenças regionais e o fato de que a oferta da educação básica nos municípios é compartilhada pelos governos municipais e estaduais, um indicador municipal é importante para apontar as diferenças e os contextos que requerem ações conjuntas entre as esferas de governo.

Além desta introdução e das considerações finais, este artigo está estruturado em outras três seções. A primeira apresenta o referencial teórico. A segunda descreve as estratégias metodológicas e os procedimentos para a construção do ISE-M. Na terceira são analisadas as características dos municípios segundo o ISE-M nas regiões brasileiras.

\section{REFERENCIAL TEÓRICO}

O nível socioeconômico dos indivíduos é considerado um aspecto determinante nas pesquisas sociais (Alves e Soares, 2009). Na área da educação, este se tornou um determinante-chave, sobretudo devido às 
pesquisas realizadas a partir da década de 1960 que concluíram que o desempenho educacional está fortemente associado à origem socioeconômica dos alunos (Coleman et al., 1966; Plowden Report, 1967; Mosteller e Moynihan, 1972; Jencks, 1972; Bowles e Gintis, 2008; Madaus, Airasian e Kellaghan, 2008; Rutter et al., 1979; Willms, 1992; Lee, 2000; Hanushek, 1979; 1986).

No Brasil, apesar de ser um movimento que se fortaleceu apenas na década de 1990, época em que foi instituído o Sistema Nacional de Avaliação da Educação Básica (Saeb), as investigações sobre fatores associados ao desempenho escolar começaram a formar um importante núcleo de conhecimento a partir de dados nacionais (Alves e Franco, 2008). Neste sentido, o trabalho de Soares (2004) descreve o desempenho cognitivo de alunos no Saeb e verifica que há grandes desigualdades no desempenho entre os alunos das diferentes regiões, raça / cor e níveis socioeconômicos. O estudo vai além ao mostrar que o sistema de ensino não contribui para reverter tal quadro quando conclui que o nível de proficiência medido pelo Saeb está fortemente associado à posição social do aluno e que, considerando os processos relacionados aos professores (nível de formação, salário, percepção dos problemas da escola, relação com o diretor e com a equipe, expectativas em relação ao trabalho etc.) e à escola (prédio, limpeza, segurança, qualidade das salas, equipamentos etc.), "a escola dos alunos de pior desempenho é pior que a dos alunos de melhor desempenho" (Soares, 2004:18).

Em outro estudo, Soares e Andrade (2006) investigaram o efeito da escola para os diferentes grupos sociais na cidade de Belo Horizonte e também verificaram a existência de relação entre a origem socioeconômica e o desempenho dos alunos. Os autores concluíram que há escolas que conseguem elevar o desempenho de estudantes que vivem em contextos desfavorecidos enquanto outras só produzem bons resultados na presença de forte iniquidade social. Andrade e Laros (2007), Soares e Alves (2003) e a coletânea apresentada em Franco (2001) são algumas entre uma quantidade relevante de pesquisas que verificaram a relação entre os referidos fatores no contexto brasileiro.

\section{A Construção de Indicadores Socioeconômicos}

Os indicadores socioeconômicos são medidas que descrevem a posição que os indivíduos ou famílias ocupam em uma hierarquia social com base no acesso, posse ou controle de fatores que caracterizam ri- 
queza, poder e status social (Sirin, 2005). Estas medidas são um dos construtos mais estudados em ciências sociais e têm sido utilizadas tradicionalmente pela sociologia americana e inglesa em pesquisas que analisam a estratificação e a mobilidade social dos indivíduos nas sociedades. Em geral, estes indicadores são operacionalizados por meio de uma combinação de variáveis: renda, nível de escolaridade, tipo de ocupação, posse de bens e acesso a itens de conforto no domicílio, estado civil e configuração da família, qualidade da casa, status da região de moradia, comportamento social e político etc. (Duncan, 1961; White, 1982; Alves e Soares, 2009).

Um marco nas pesquisas nesta área foi o trabalho de Duncan (1961). O autor utilizou as variáveis renda e escolaridade contidas no censo populacional americano de 1950 e outra variável referente ao prestígio das ocupações para, por meio de regressão múltipla, propor um índice socioeconômico ${ }^{4}$ para a população daquele país. Esta pesquisa se tornou um dos trabalhos mais influentes e uma referência metodológica para as pesquisas contemporâneas de tal forma que outros autores como Stevens e Featherman (1981) e Nakao e Treas (1992) se propuseram a atualizá-la em diferentes momentos ou se basearam nela para propor novos indicadores, como Ganzeboom, Graaf e Treiman (1992). Outros ainda, como Cirino et al. (2002), por exemplo, aplicaram metodologia parecida para analisar o status socioeconômico em diferentes países.

Não há consenso quanto às variáveis mais adequadas para aferir o nível socioeconômico, tampouco quanto aos procedimentos metodológicos. No entanto, de forma geral, o nível de escolaridade, a ocupação e o nível de renda têm sido os principais descritores (Sirin, 2005). Como observam Alves e Soares (2009), ao utilizar estas variáveis, as pesquisas assumem o pressuposto que a educação é o elemento-chave da qualificação para o trabalho (ou o pré-requisito para as ocupações com maior prestígio) e a renda é a consequência, ou seja, são a causa e o efeito da posição socioeconômica do indivíduo. Quanto aos procedimentos, métodos alternativos para fazer face à complexidade das novas realidades da sociedade ou em função de críticas a estudos anteriores, como Osborn (1987), têm colaborado para o avanço da área.

O índice de status social proposto por Hollingshead (1975) utiliza quatro fatores: educação (nível de escolaridade completo), sexo, ocupação e estado civil. O autor considerou sete níveis de escolaridade, classifi- 
cou as ocupações em nove níveis e formou categorias de estado civil (combinando as categorias: estado civil; trabalhador e não trabalhador; com renda ou sem renda). A variável sexo foi utilizada apenas como controle. Foram atribuídos pesos às variáveis educação e ocupação. Assim, o índice para os indivíduos é calculado a partir dos níveis da ocupação e escolaridade ponderados pelo peso dos fatores. O status da família considera o estado civil e, em caso de casal, o nível de formação e ocupação média dos cônjuges.

O trabalho de Osborn (1987) apresenta um método alternativo para construção de um índice da posição social das famílias. Oíndice é composto por sete variáveis: ocupação e nível de escolaridade dos chefes da família, tipo de moradia, house tenure ${ }^{5}$, quantidade de pessoas por quarto, carro e telefone. O autor argumenta sobre as vantagens do índice no que se refere à confiabilidade e sensibilidade para avaliar o status socioeconômico em casos em que não há informações relevantes sobre a ocupação dos indivíduos.

O International Socio-Economic Index of Occupational Status (ISEI) proposto por Ganzeboom, Graaf e Treiman (1992) foi construído a partir da comparação de variáveis relativas à educação, ocupação e renda de 73.901 trabalhadores do sexo masculino em 16 países. Os autores atribuíram escores e formaram 271 categorias de ocupações, de forma a maximizar a ocupação enquanto variável interveniente da renda e nível de escolarização. A proposta dos autores é inferir e comparar o status social de indivíduos de diferentes países apenas com a informação da ocupação, sem a necessidade de coletar dados sobre renda e escolaridade. Devido às suas características, o ISEI tem sido utilizado em avaliações educacionais internacionais como o Programme for International Student Assessment (PISA) ${ }^{6}$, em que o status socioeconômico do aluno é inferido por meio da informação da ocupação dos pais. O ISEI foi atualizado e padronizado de acordo com a International Stardard Classification of Occupation de 1988 (ISCO88) $^{7}$ em Ganzeboom e Treiman (1996).

No Brasil, entre os trabalhos que utilizaram dados sobre rendimento e educação dos levantamentos demográficos como Duncan (1961), destacam-se os de Scalon (1998), Jannuzzi (2000), Santos (2005) e Pastore e Silva (2000). Scalon (1998) apresenta um debate teórico entre neomarxitas e neoweberianos, com base nos estudos empíricos de estratificação de Wright e Goldthorpe, para embasar sua proposta de classifi- 
cação de estratos sociais. Para tanto, utilizou dados de rendimento e educação da Pesquisa Nacional por Amostra de Domicílios (PNAD) 1988 de indivíduos do sexo masculino entre 20 e 64 anos. A autora utilizou a análise de conglomerados com método hierárquico para definir estratos a partir das duas variáveis objetivas e realizou análises loglineares para reduzir o número de classificações e encontrar um modelo de classificação que melhor representasse a estrutura de classes no Brasil. Este estudo tomou como referência as 18 classes de ocupação propostas por Valle Silva (1992, apud Scalon, 1998) e, ao final, propôs a classificação das 342 ocupações em nove classes ocupacionais. Nestes trabalhos, além do aspecto objetivo dos fenômenos renda e educação medidos pelas variáveis da PNAD, os autores buscaram classificações capazes de agrupar indivíduos com posições de mercado e trabalho similares e que contemplassem características teóricas que constituem elementos relevantes para a estrutura de posições sociais, tais como: proprietário/não proprietário; qualificado/não qualificado; trabalho manual/não manual; rural/urbano; autonomia/não autonomia, controle/não controle etc.

O trabalho de Jannuzzi (2000) utiliza uma base de dados maior (censos de 1980 e 1991 e as PNADs da década de 1990) para propor e comparar dois índices. Inicialmente, o autor calcula a mediana da renda e educação para cada ocupação a fim de construir o índice socioeconômico posicional (Isep), que é o status médio dessas duas medidas de tendência central (o autor padronizou o índice numa escala de 0 a 100). Em seguida, Jannuzzi propõe uma medida de distância socioeconômica utilizando as mesmas variáveis. Para isso, utiliza a análise fatorial, com o método de componentes principais para reduzir os dados, e os escores fatoriais, padronizados entre 0 e 100 para obter o índice socioeconômico distancial (Ised). O autor verifica a consistência e coerência dos resultados entre os dois índices e, com base nas 18 classes de Valle Silva (1992, apud Jannuzzi, 2000), propõe o agrupamento das ocupações em cinco estratos sociocupacionais.

Igualmente, Pastore e Silva (2000) utilizaram em seu Índice de Status Socioeconômico (ISS) dados da PNAD de 1996 e as variáveis "renda total" e "anos de estudo". Para cada ocupação foi calculada a média das variáveis. Em seguida, o resultado das ocupações foi padronizado numa escala de 0 a 100 para facilitar a comparabilidade. O ISS é a média dos escores em cada variável e indica a posição do indivíduo no mercado de trabalho. A partir dos escores, as ocupações foram agrega- 


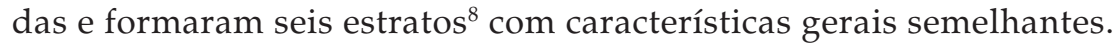
Metodologias semelhantes a esta têm sido aplicadas à educação para inferir o status socioeconômico dos alunos, como no vestibular da Universidade Federal de Minas Gerais (UFMG), citado por Alves e Soares (2009), que uma das perguntas do questionário contextual indaga aos alunos sobre as características gerais da ocupação dos pais. Dessa forma, a posição da família é inferida com base no estrato ocupacional em que os pais se enquadram.

Entretanto, as medidas do nível socioeconômico para alunos sofrem limitações diante das dificuldades em obter informações precisas sobre a renda e a ocupação dos pais junto aos alunos. Para contornar este óbice, as pesquisas e avaliações educacionais geralmente utilizam a estratégia de medir a riqueza da família de forma indireta, por meio da verificação de itens de consumo das famílias e escolaridade dos pais. Neste sentido, o Critério de Classificação Econômica Brasil (CCEB), desenvolvido pela Associação Nacional das Empresas de Pesquisa (Anep), mais conhecido como "Critério Brasil", fornece uma metodologia alternativa que tem sido bastante utilizada para conhecer o nível socioeconômico das pessoas de forma indireta. O indicador é calculado a partir da atribuição de pontos à quantidade de bens (TV, rádio, banheiro, carro, empregada doméstica, aspirador, máquina de lavar, vídeo/DVD, geladeira e freezer) que os indivíduos possuem, além de considerar o nível de instrução do chefe da família. Para cada bem possuído há uma pontuação, e as sete classes são definidas pela soma dos pontos (Pereira, 2004). Apesar de ter sido concebido para avaliar o poder de compra de grupos de consumidores e, consequentemente, orientar esforços de marketing e vendas das empresas, o indicador tem sido útil às pesquisas educacionais, como, por exemplo, Inep (2005), que adotam metodologias baseadas no "Critério Brasil" para descrever as características socioeconômicas dos alunos.

Mesmo assim, como afirmam Alves e Soares (2009), há limitações nas medidas indiretas do status socioeconômico da família. Uma delas é a comparação temporal, uma vez que itens (como DVD, telefones e computador) inicialmente acessíveis apenas às camadas mais privilegiadas, com o tempo, tornam-se populares e passam a não diferenciar os estratos sociais. A outra limitação é espacial, uma vez que podem refletir o hábito de consumo de determinadas regiões mais do que de outras e, desse modo, captar pouco o status socioeconômico de algumas realidades sociais, não permitindo uma comparação adequada entre elas. 
Os autores também advertem que o nível de escolaridade para a geração mais jovem não é um indicador tão robusto da posição social como no passado, devido à expansão do acesso à escola nas últimas décadas. O argumento é que atualmente a diferenciação social não se dá apenas pelos anos de estudo (ou "quantidade" da educação), mas também pela diferença da qualidade da educação a que se tem acesso.

Em que pesem estas considerações, algumas propostas de indicador socioeconômico para alunos baseadas em medidas de riqueza indireta são apresentadas por Soares (2004) e Soares e Andrade (2006). O estudo de Soares (2004) propôs uma medida no nível socioeconômico (NSE) com base na metodologia utilizada pelo PISA, que faz uso de dados dos alunos referentes a quatro aspectos: (a) exclusão social - presença ou ausência de abastecimento de água, energia elétrica e pavimentação na rua; (b) escolaridade dos pais - número máximo de anos de estudo do pai e da mãe; (c) evidência da riqueza da família - número de pessoas por quarto (em que uma menor relação indica melhor condição), existência de empregada doméstica; número de automóveis na residência do aluno; (d) existência de bens educacionais em casa - lugar calmo para estudar, jornal diário, revista, enciclopédia, atlas, dicionário, calculadora e acesso à internet. $\mathrm{O}$ autor agregou estas variáveis em um único índice via análise fatorial.

A metodologia proposta por Soares e Andrade (2006) utilizou dados dos "itens de conforto" existentes na casa dos estudantes (TV em cores, videocassete, máquina de lavar, computador, automóvel, banheiro, empregada doméstica, aspirador de pó, TV a cabo, telefone fixo ou celular, geladeira duplex, freezer e sala), indicadores de renda (renda do grupo familiar, ocupação do pai e da mãe); e escolaridade dos pais. Com base nestas variáveis, os autores calcularam um indicador para cada aluno e outro agregado por escola por meio da Teoria de Resposta ao Item (TRI) a fim de controlar o efeito da posição social dos alunos nas avaliações do sistema de ensino.

Com o mesmo propósito, o indicador socioeconômico apresentado por Alves e Soares (2009) foi construído a partir de informações de 4,6 mil alunos $^{9}$ das redes pública e privada de Belo Horizonte. $\mathrm{O}$ indicador contemplou os aspectos educação, ocupação, região de moradia e renda da família dos alunos. Para isso, foram utilizadas as variáveis nível de escolaridade das mães e a ocupação do pai ou da mãe (a de maior status ocupacional), que foi localizada nas seis classes propostas por 
Pastore e Silva (2000). Para estimar a renda, em vez de utilizar itens de consumo e / ou conforto das famílias, foi utilizado o Código de Endereçamento Postal (CEP) do domicílio dos alunos. A hipótese subjacente é que as famílias com nível socioeconômico semelhante se aglutinam por região de moradia. A partir deste código foi calculada a renda média dos responsáveis pelos domicílios dos setores censitários (definidos pelo Instituto Brasileiro de Geografia e Estatística - IBGE) a que pertencem os CEPs para estimar a renda das famílias dos alunos. A variável renda para compor o indicador foi apresentada em cinco faixas. Estas três variáveis categóricas foram incluídas em um modelo de TRI que calculou o indicador representativo do status socioeconômico dos alunos.

Assim, os procedimentos de construção de medidas de status socioeconômico encontrados na literatura pesquisada nortearam a proposta de indicador municipal apresentada neste artigo.

\section{ASPECTOS METODOLÓGICOS}

A construção do ISE-M no presente trabalho foi realizada por meio de uma pesquisa quantitativa descritiva. Como informado, o índice que visa descrever, de forma agregada, o contexto econômico e/ou social dos alunos das escolas públicas nos municípios brasileiros foi proposto neste nível para servir como uma medida suficientemente ampla para ser analisada em contraponto com políticas educacionais relacionadas ao financiamento, avaliação e análise da infraestrutura educacional das redes de ensino (condições dos prédios escolares, disponibilidades de equipamentos e materiais necessários ao ensino de qualidade, existência de espaços educativos como laboratórios e bibliotecas e condições de trabalho dos docentes - formação, salário e carreira).

Para isso, foram utilizados dados secundários referentes aos bens e serviços disponíveis nas casas dos alunos e o nível de escolaridade dos pais ou responsáveis, levantados por meio do questionário contextual preenchido pelos participantes da Prova Brasil ${ }^{10}$ em 2011.

\section{Variáveis}

Com base nos estudos apresentados na seção anterior, que mediram o status socioeconômico a partir dos fatores renda, ocupação e educação dos indivíduos, neste artigo, de acordo com as possibilidades da fonte utilizada, foram selecionadas as questões da Prova Brasil ${ }^{11}$ que descre- 
viam, de forma indireta, a renda (por meio da descrição dos recursos econômicos) e a educação (pelo nível de escolaridade dos pais) das famílias dos alunos para operacionalizar a construção do ISE-M. O Quadro 1 apresenta as questões selecionadas e as variáveis geradas a partir delas.

Como mostra o quadro, a Prova Brasil levantou dados por aluno utilizando variáveis categóricas (em escala ordinal). Por isso, para obter as variáveis métricas que formaram o indicador, foi necessário agregar os dados em nível municipal e mudar o elemento de análise dos dados originais. Isso foi possível por meio da análise de frequências absolutas e relativas das respostas dos alunos em cada item das questões do questionário. Em seguida, foram atribuídos pesos à quantidade de itens disponíveis nos domicílios para calcular a média ponderada dos municípios em cada questão. Por exemplo: a questão 5 indaga se na casa dos alunos não tem ou tem uma, duas, três ou mais televisões em cores. Neste caso, foram atribuídos os pesos zero para "não tem" e peso um, dois ou três, respectivamente, para as demais alternativas. Desse modo, pelo resultado da média ponderada, cada município obteve uma pontuação entre zero e três, onde zero indica que todos os alunos do município não têm televisão e três indica que todos têm três ou mais televisores em cores. Em seguida, o resultado da média ponderada em cada município foi padronizado para uma escala com valor mínimo igual a zero e máximo igual a um (a padronização foi necessária porque as questões apresentavam formatos diferentes e, consequentemente, escalas diferentes de pontuação). Assim foi gerada a variável "Televisão".

Este processo guarda certa semelhança com o procedimento adotado pelo "Critério Brasil", uma vez que considera a quantidade de itens e não apenas a disponibilidade ou não dos descritores do contexto socioeconômico. Procedimento análogo foi realizado para obter as demais variáveis que formaram o ISE-M, exceto a variável "escolaridade do pai" e "escolaridade da mãe" em que não foram consideradas todas as alternativas de resposta, a fim de se obter maior variabilidade (e, consequentemente, maior poder de discriminação entre os municípios). Nestas variáveis foram consideradas apenas as alternativas relativas à escolarização em nível médio e superior.

Com o intuito de dar maior confiabilidade ao indicador, observou-se a quantidade de respostas válidas ${ }^{12}$ em cada variável. Após este procedimento, só foram consideradas no cálculo do ISE-M de cada 
Thiago Alves, Maria Aparecida Gouvêa e Adriana Backx Noronha Viana

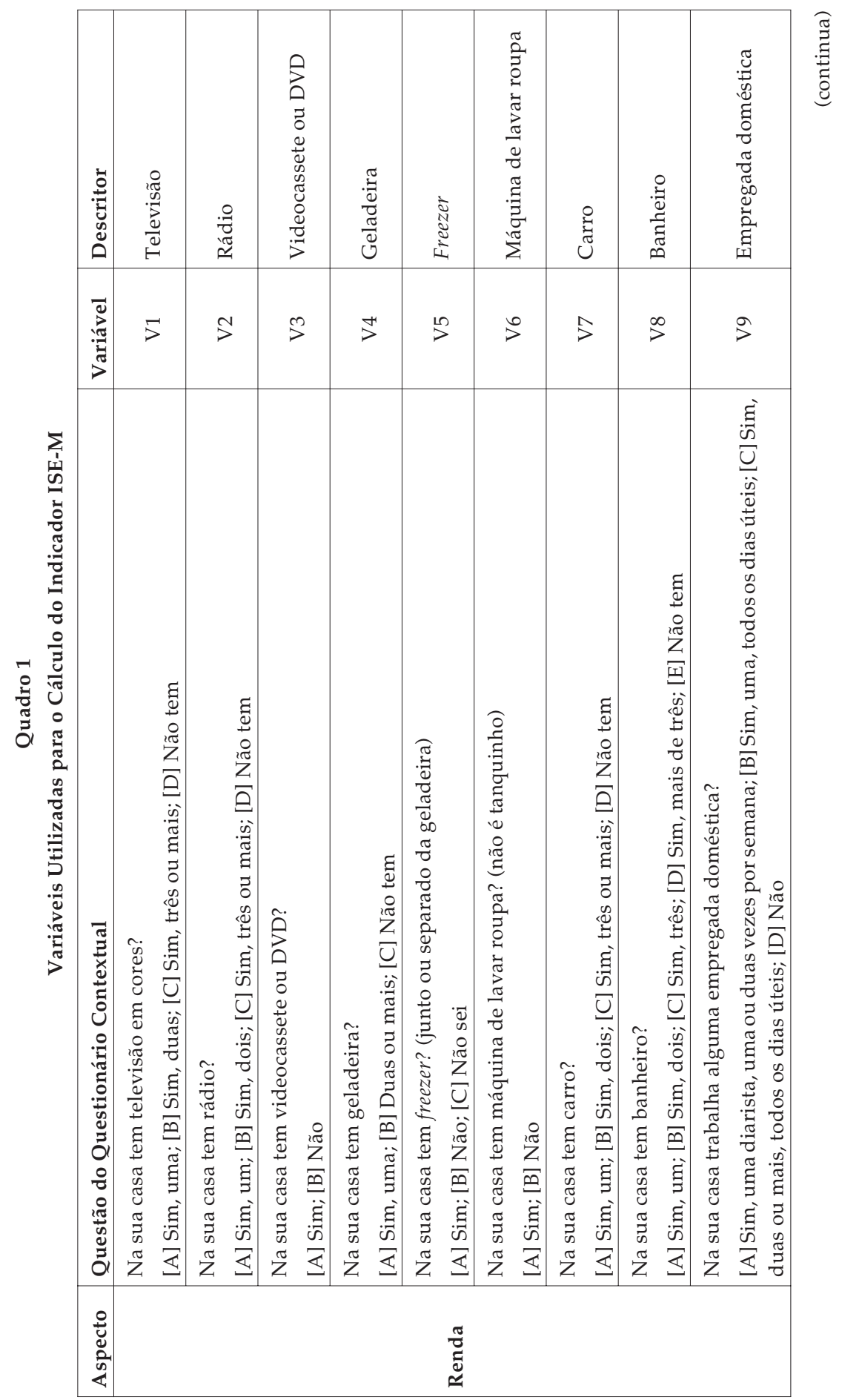

140 DADOS - Revista de Ciências Sociais, Rio de Janeiro, vol. 57, no 1, 2014 
Proposta de um Indicador Socioeconômico...

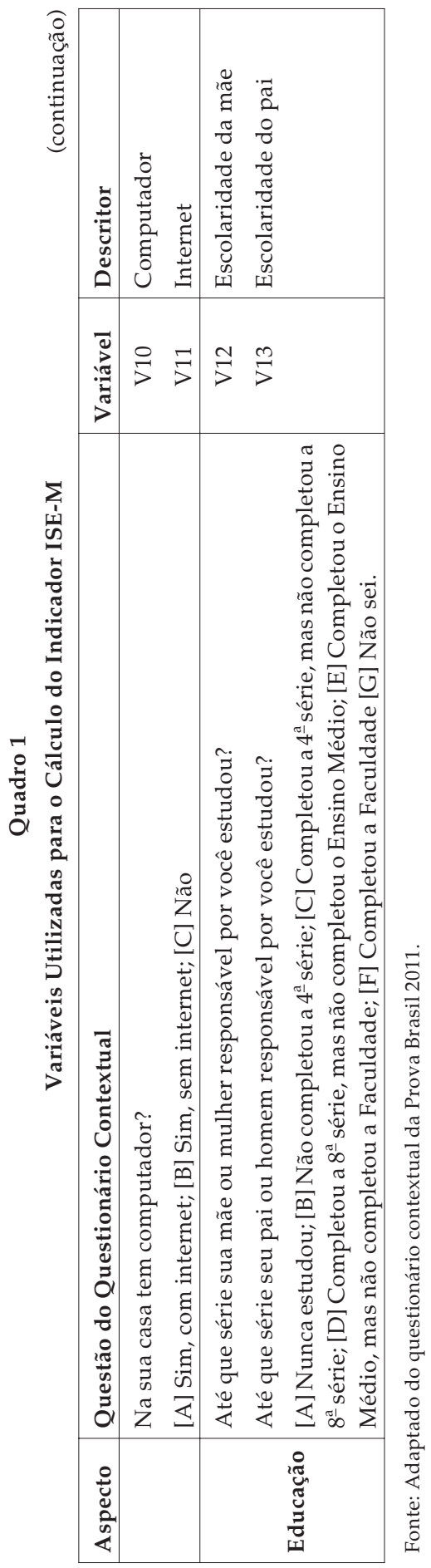

DADOS - Revista de Ciências Sociais, Rio de Janeiro, vol. 57, nº 1, 2014 
município as variáveis que contavam com pelo menos vinte respostas válidas ${ }^{13}$. Tal estratégia visou não subestimar ou superestimar o indicador em caso de grande número de respostas inválidas.

\section{Procedimentos para Calcular o Indicador}

As informações das variáveis foram reduzidas por meio de Análise Fatorial, utilizando o método de componentes principais para extração dos fatores e o método de rotação varimax. Esta foi uma estratégia alternativa a outros métodos também utilizados para construção de indicadores, como por exemplo, a TRI ${ }^{14}$ utilizada em outros trabalhos sobre o mesmo tema. Tal escolha foi realizada uma vez que, de acordo com Pasquali e Primi (2003), um dos pressupostos básicos para aplicação da TRI consiste na unidimensionalidade, o que não pode ser garantido para os dados utilizados neste trabalho. Além disso, o que diferencia os dois métodos (TRI e análise fatorial) é a interpretação dos resultados. A Análise Fatorial exploratória é empregada para encontrar o menor número possível de variáveis hipotéticas que ilustram as relações dentro de um grande número de variáveis consideradas inicialmente, ou seja, consiste em uma técnica de redução de dados. A TRI objetiva modelar e entender a interação entre respondentes e itens. No presente estudo, o interesse consistiu em construir um indicador com base nas variáveis consideradas, o que justifica o uso da análise fatorial.

Após a definição da técnica para análise dos dados, em procedimento análogo ao de Fachel (1976), as cargas fatoriais de cada fator foram ponderadas pelo percentual de variância explicada nos respectivos fatores e, assim, foi gerada uma pontuação para cada município. Para facilitar a interpretação, o escore obtido no fator renda foi padronizado para uma escala de valores entre zero e um.

\section{Apresentação dos Resultados}

Obtido o indicador, foi explorado o potencial da medida para destacar e diferenciar as realidades socioeconômicas dos alunos no país. Inicialmente, foram identificados os municípios com as melhores e piores colocações no ranking formado pelo ISE-M. Também foram descritas algumas características destas localidades. Em seguida, para facilitar a apresentação dos resultados, os municípios foram classificados em cinco níveis formados pelo $20^{\circ}, 40^{\circ}, 60^{\circ}$ e $80^{\circ}$ percentil do indicador. Dessa forma, o primeiro nível agrupou os municípios cujo conjunto de 
alunos tem status socioeconômico menos favorecido, e o quinto nível, os mais favorecidos. $\mathrm{O}$ passo seguinte consistiu na análise dos resultados em cada Estado, a fim de compreender as semelhanças e diferenças regionais. Por fim, os municípios classificados nos cinco níveis do ISE-M formaram um mapa do contexto socioeconômico dos alunos das escolas públicas nos municípios brasileiros.

\section{Validação}

Alguns trabalhos que propuseram medidas socioeconômicas realizaram procedimentos de validação por meio da análise da correlação entre os achados dos índices propostos e outras medidas da mesma natureza (Ganzeboom e Treiman, 1996; Hollingshead, 1975; Cirino et al., 2002, por exemplo). Para validar o ISE-M foi adotado o Índice Firjan de Desenvolvimento Municipal (IFDM) do ano de 2012 (ano base 2010), calculado pela Federação das Indústrias do Estado do Rio de Janeiro (Sistema Firjan) como parâmetro. Este indicador é calculado anualmente desde 2000 com o objetivo de fazer um acompanhamento socioeconômico dos municípios e suprir lacunas de informações neste nível com tal periodicidade (Firjan, 2010). É composto por variáveis que descrevem três fatores: emprego e renda; educação; e saúde ${ }^{15}$. Dessa forma, é apresentado um indicador específico para cada fator e um geral (o IFDM), formado pela média dos três anteriores. Os resultados do ISE-M foram comparados com IFDM-emprego\&renda, que é formado pelo aspecto renda (que de certa forma foi captado no ISE-M pelos recursos econômicos das famílias dos alunos) e emprego (que, em geral, está associado ao nível de escolaridade e foi medido pelo ISE-M com base na escolaridade dos pais).

\section{ANÁLISE DOS RESULTADOS}

Para o cálculo do ISE-M, foram utilizados 3.899.327 ${ }^{16}$ questionários constantes nos arquivos dos microdados da Prova Brasil 2011 disponibilizados pelo Inep/ $\mathrm{MEC}^{17}$. Estes alunos estavam matriculados em 46.290 escolas urbanas ${ }^{18}$ ( $85 \%$ do total de escolas desta etapa de ensino e localização), sendo $0,1 \%$ federais, $45,9 \%$ estaduais e $54 \%$ municipais; $52,8 \%$ dos alunos cursavam o 5 o ano e $47,2 \%$ cursavam o 9 o ano; $59,4 \%$ estudavam no turno matutino, $39,2 \%$ no vespertino e $1,4 \%$ no noturno; e estavam situados em 5.492 municípios das 27 unidades da federação.

Inicialmente, antes do cálculo do ISE-M propriamente dito, foi calculado o coeficiente de variação para identificar as variáveis com maior po- 
tencial de discriminação dos casos. Este procedimento visou minimizar uma limitação que os dados levantados por meio de questionários contextuais aplicados a alunos podem apresentar para análise do status socioeconômico, uma vez que, como alertam Alves e Soares (2009), alguns itens se popularizam com o passar do tempo e passam a não diferenciar a posição social dos indivíduos. Desse modo, as variáveis cujo coeficiente estava abaixo de $20 \%$, tais como televisão (V1), videocassete ou DVD (V3), geladeira (V4) e banheiro (V8), foram descartadas (veja Apêndice 1). Em seguida foi analisada a matriz de correlação das nove variáveis restantes. Verificou-se que a variável "empregada doméstica" (V9) apresentava baixas correlações com as demais (veja Apêndice 2) e que, em virtude disso, não seria pertinente sua inclusão, por não atender uma das premissas da técnica utilizada.

Realizados estes procedimentos, a etapa seguinte consistiu na redução, por meio da análise fatorial, do volume de informações dos alunos de cada município descritas em oito variáveis: seis relativas aos recursos econômicos das famílias dos alunos (fator renda) e duas representativas da escolaridade dos pais (fator educação). Os resultados satisfatórios em todas as estatísticas (veja Apêndice 3) mostram que a aplicação da técnica ao conjunto de dados foi pertinente.

Assim, o ISE-M foi gerado para 5.333 municípios ${ }^{19} \mathrm{e}$, como dito na seção anterior, foi apresentado numa escala de valores padronizados de zero a um (em que um foi atribuído ao município cujos alunos das escolas públicas urbanas possuem melhor nível socioeconômico e zero àquele com o pior nível socioeconômico ${ }^{20}$. A média dos municípios no índice ISE-M foi 0,436, sendo que $50 \%$ deles obtiveram indicador de até 0,434 (mediana). Os municípios foram agrupados em cinco níveis (divididos em cinco partes iguais por meio do $20^{\circ}$, 40 으, $60^{\circ}$ e e $80^{\circ}$ percen$\mathrm{til}^{21}$ ), de acordo com a performance no indicador. A Tabela 1 descreve as características predominantes dos municípios em cada nível do indicador. Nela está indicado o percentual de alunos que possuem os bens de consumo descritos pelas variáveis que compõem o indicador e o percentual de pais que concluíram pelo menos o nível médio nos municípios situados nos cinco níveis do ISE-M.

Inicialmente, a tabela mostra que há itens com acesso mais disseminado entre os estratos socioeconômicos como, por exemplo, rádio e videocassete ou DVD. Outros itens, como carro, computador e internet, estão fora do acesso da maior parte das famílias dos estudantes das escolas públicas brasileiras. Destaca-se também na tabela o fato de que, 
Proposta de um Indicador Socioeconômico...

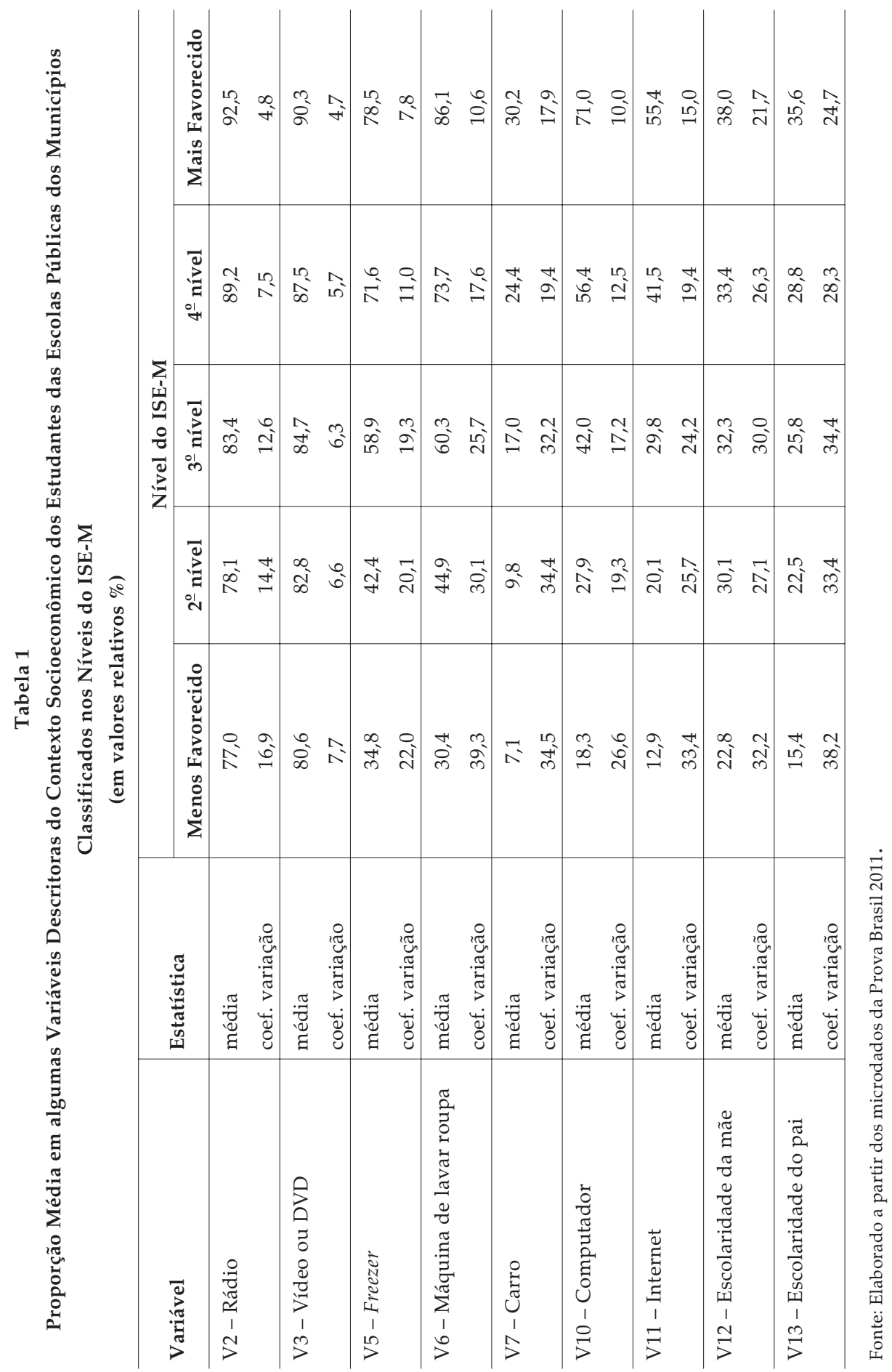

DADOS - Revista de Ciências Sociais, Rio de Janeiro, vol. 57, nº 1, 2014 
em média, apenas pouco mais de um terço dos pais e mães destes alunos concluíram a formação em nível médio ou superior, inclusive nos municípios que compõem o melhor nível (ou seja, o nível de formação dos pais é baixo e não varia muito entre os municípios). Detalhando um pouco mais os microdados, foi possível verificar que apenas $24,3 \%$ das mães e 22,1\% dos pais dos alunos das escolas públicas urbanas avaliadas concluíram o ensino médio e somente 13\% das mães e 13,3\% dos pais têm formação em nível superior (informações calculadas somente a partir das respostas válidas ${ }^{22}$. O nível de escolaridade dos pais é um aspecto importante para direcionar as políticas públicas educacionais, uma vez que estudos como Barros et al. (2001) e Hasenbalg e Silva (2000) mostram forte associação entre a educação dos pais e dos filhos no Brasil, em outras palavras, que ocorre transmissão intergeracional da condição educacional das famílias.

Ainda sobre os resultados apresentados na Tabela 1, vale ressaltar também que algumas variáveis apresentam menores diferenças entre os municípios classificados entre os níveis inferiores e superiores do ISE-M (rádio e escolaridade dos pais, por exemplo), enquanto em outras a diferença da média entre o quinto e o primeiro nível é superior a três vezes (por exemplo, a variável carro, computador e internet). Verificou-se, por meio do teste $\mathrm{F}$ (com finalidade descritiva), que as variáveis que mais discriminam a diferença de média entre os grupos são, respectivamente, computador, internet, freezer, carro, máquina de lavar roupa, rádio, escolaridade do pai e escolaridade da mãe (ver Apêndice 4$)$.

Para se ter uma ideia das características dos municípios classificados de acordo com os resultados do indicador, São Caetano do Sul-SP (ISE-M = 1,00), Ernestina-RS (ISE-M = 0,99) e Águas de São Pedro-SP (ISE-M $=0,94$ ) foram as localidades que obtiveram os melhores desempenhos na medida socioeconômica. Segundo dados do IBGE, o município melhor colocado tem uma população estimada em 149.263 habitantes (Censo 2010) e PIB per capita de $\mathrm{R} \$ 78.438^{23}$ (a preços correntes de 2011). Cerca de $48,6 \%$ das mães e $39,3 \%$ dos pais dos alunos que realizaram a Prova Brasil em 2011 neste município concluíram o ensino médio ou superior. Por outro lado, os municípios com os piores desempenhos no indicador foram Sambaíba-MA (ISE-M =0,00), Bom Princípio do Piauí-PI (ISE-M = 0,01) e Pau D'Arco do Piauí-PI (ISE-M = 0,03). Sambaíba é um município com 5.487 habitantes e PIB per capita de $\mathrm{R} \$ 16.845$. Apenas $11,5 \%$ das mães e $10 \%$ dos pais dos alunos concluí- 
Proposta de um Indicador Socioeconômico...

ram o ensino médio ou superior. A Tabela 2 compara algumas características dos municípios com os melhores e piores resultados no ISE-M.

Tabela 2

Características dos Municípios com Desempenhos Extremos no ISE-M

\begin{tabular}{|c|c|c|c|c|c|c|}
\hline \multirow[t]{2}{*}{ Posição } & \multirow[t]{2}{*}{ Município } & \multirow[t]{2}{*}{ ISE-M $^{1}$} & \multirow[t]{2}{*}{$\begin{array}{l}\text { Popula- } \\
\text { ção }^{2}\end{array}$} & \multirow{2}{*}{$\begin{array}{l}\text { PIB per } \\
\text { capita } \\
(\mathrm{R} \$)^{3}\end{array}$} & \multicolumn{2}{|c|}{$\begin{array}{c}\text { Concluíram Ensino } \\
\text { Médio ou Su- }^{\text {perior }} \\
\text { perio }^{1}\end{array}$} \\
\hline & & & & & mães & pais \\
\hline $1^{\circ}$ & São Caetano do Sul-SP & 1,00 & 149.263 & 78.438 & $49 \%$ & $39 \%$ \\
\hline $2^{\underline{0}}$ & Ernestina-RS & 0,96 & 3.088 & 24.528 & $70 \%$ & $37 \%$ \\
\hline $3^{\mathrm{o}}$ & Águas de São Pedro-SP & 0,91 & 2.707 & 23.032 & $48 \%$ & $43 \%$ \\
\hline $5.331^{\circ}$ & Pau D'Arco do Piauí-PI & 0,03 & 3.757 & 3.696 & $4 \%$ & $2 \%$ \\
\hline $5.332^{\circ}$ & Bom Princípio do Piauí-PI & 0,01 & 5.304 & 5.997 & $14 \%$ & $5 \%$ \\
\hline $5.333^{\circ}$ & Sambaíba-MA & 0,00 & 5.487 & 16.845 & $12 \%$ & $10 \%$ \\
\hline
\end{tabular}

Fonte: (1) Calculado a partir dos microdados da Prova Brasil 2011; (2) Censo 2010; (3) @cidade IBGEa preços correntes de 2011. Disponível em http://cidades.ibge.gov.br/xtras/home.php?lang=

Como mostram os dados da Tabela 2, os municípios cujo conjunto de alunos tem maior status socioeconômico têm maior PIB per capita. Seguindo estas evidências, a associação entre o ISE-M e o PIB per capita foi verificada pelo coeficiente de correlação de Pearson $(r=0,464)$. A associação se mostrou mais expressiva quando as variáveis foram analisadas sob a forma categórica a partir dos cinco níveis das variáveis formados pelos $20^{\circ}$, $40^{\circ}, 60^{\circ}$ e $80^{\circ}$ percentil (correlação de Kendall = 0,566 e Sperman $=0,765$.

Vale ressaltar também que foi verificada correlação positiva expressiva entre o ISE-M e o Índice de Desenvolvimento da Educação Básica $(\mathrm{Ideb})^{24}$ - coeficiente de correlação de Pearson igual a 0,452 para o 5o ano da rede pública (escolas estaduais e municipais), 0,562 para o 9o ano da rede pública. Estes resultados ratificam os achados de pesquisas que apontaram forte associação entre desempenho educacional e origem socioeconômica dos alunos, tais como Coleman et al., 1966; Rutter et al., 1979; Willms, 1992; Lee, 2000; Hanushek, 1979; 1986, entre outras.

Numa tentativa de validar o indicador proposto, os resultados do ISE-M foram comparados ao Índice Firjan-emprego\&renda. Verificou-se que há correlação de 0,527 entre os indicadores, e que, dessa forma, o ISE-M conseguiu discriminar com boa aproximação os contextos municipais (entre ISE-M e Índice Firjan geral, obteve-se $r=0,747$ ). 


\section{O ISE-M nos Contextos Regionais}

A Tabela 3 apresenta o número total de municípios por unidade da federação (UF) que obteve o ISE-M e a proporção de localidades de cada UF e região em cada nível do ISE-M, além do valor por aluno estimado no âmbito do Fundeb para o financiamento das escolas públicas em $2011^{25}$.

Com base na tabela, verifica-se que a distribuição dos municípios nos níveis do ISE-M em cada estado não é homogênea. Pelo contrário, há grande disparidade em desfavor dos estados das regiões Norte e Nordeste. Ou seja, há evidências de associação entre os níveis de ISE-M e as regiões brasileiras, como ratifica o coeficiente de contingência (Stevenson, 1986) igual a 0,753. A região Norte é caracterizada por intensa desigualdade. Apenas $6 \%$ dos municípios estão entre os mais ricos, e a maior parte em níveis inferiores ( $44,9 \%$ no segundo e $15,9 \%$ no primeiro nível). O Nordeste, que abriga quase um terço (32\%) dos municípios brasileiros, é a região onde se concentra a maior proporção de municípios com alunos de escolas públicas mais pobres: $54,3 \%$ dos municípios desta região estão entre os $20 \%$ mais desfavorecidos e $90,8 \%$ estão até no 2o nível do ISE-M. Nesta região, apenas o município de Fernando de Noronha-PE está no 5o nível. O Centro-Oeste é a região intermediária. Os municípios estão em sua maioria $(43,9 \%)$ no 3o nível e no 4o nível (41\%) do ISE-M. O melhor contexto desta região é encontrado no Distrito Federal (cuja localidade única, Brasília, está no 5o nível) e no Mato Grosso do Sul com 60,3\% das localidades no 4ํㅡ́vel. Nas regiões Sul e Sudeste, destacam-se São Paulo (51,4\%), Santa Catarina $(63,2 \%)$ e Rio Grande do Sul $(68,9 \%)$ em que a maior parte dos municípios está entre os 20\% mais favorecidos. Minas Gerais, o estado com maior número de municípios do país (mais de 15\% do total do país), merece destaque pela distribuição dos municípios em todos os níveis e maior concentração no terceiro nível $(37,9 \%)$.

Outra informação relevante apresentada na Tabela 3 é o valor estimado para investimento na formação dos alunos das escolas públicas em 2011, ou seja, os valores (em quase sua totalidade) que o Estado brasileiro investe por aluno por meio de sua política de financiamento da educação básica. Neste ponto, é preciso situar que os valores investidos em cada Estado estão muito abaixo do que os países desenvolvidos investem. Segundo dados da Organização para a Cooperação e Desenvolvimento Econômico (OCDE) de 2010 (OCDE, 2013), os países membros daquela organização investem, em média, US $\$$ ppp $9.014^{26}$ por aluno ao ano no nível equivalente ao ensino fundamental brasileiro. O Brasil, 
Proposta de um Indicador Socioeconômico...

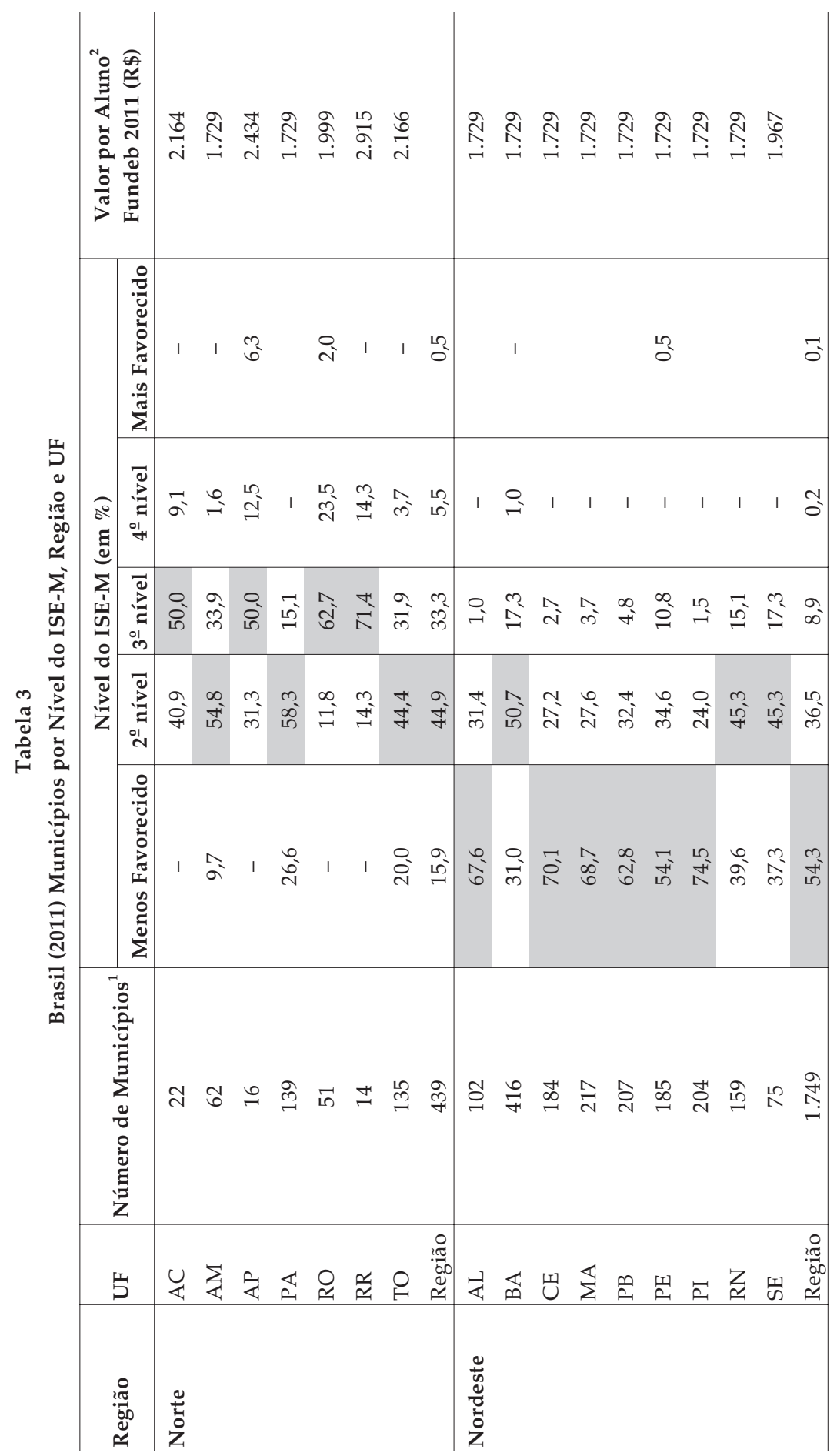


Thiago Alves, Maria Aparecida Gouvêa e Adriana Backx Noronha Viana

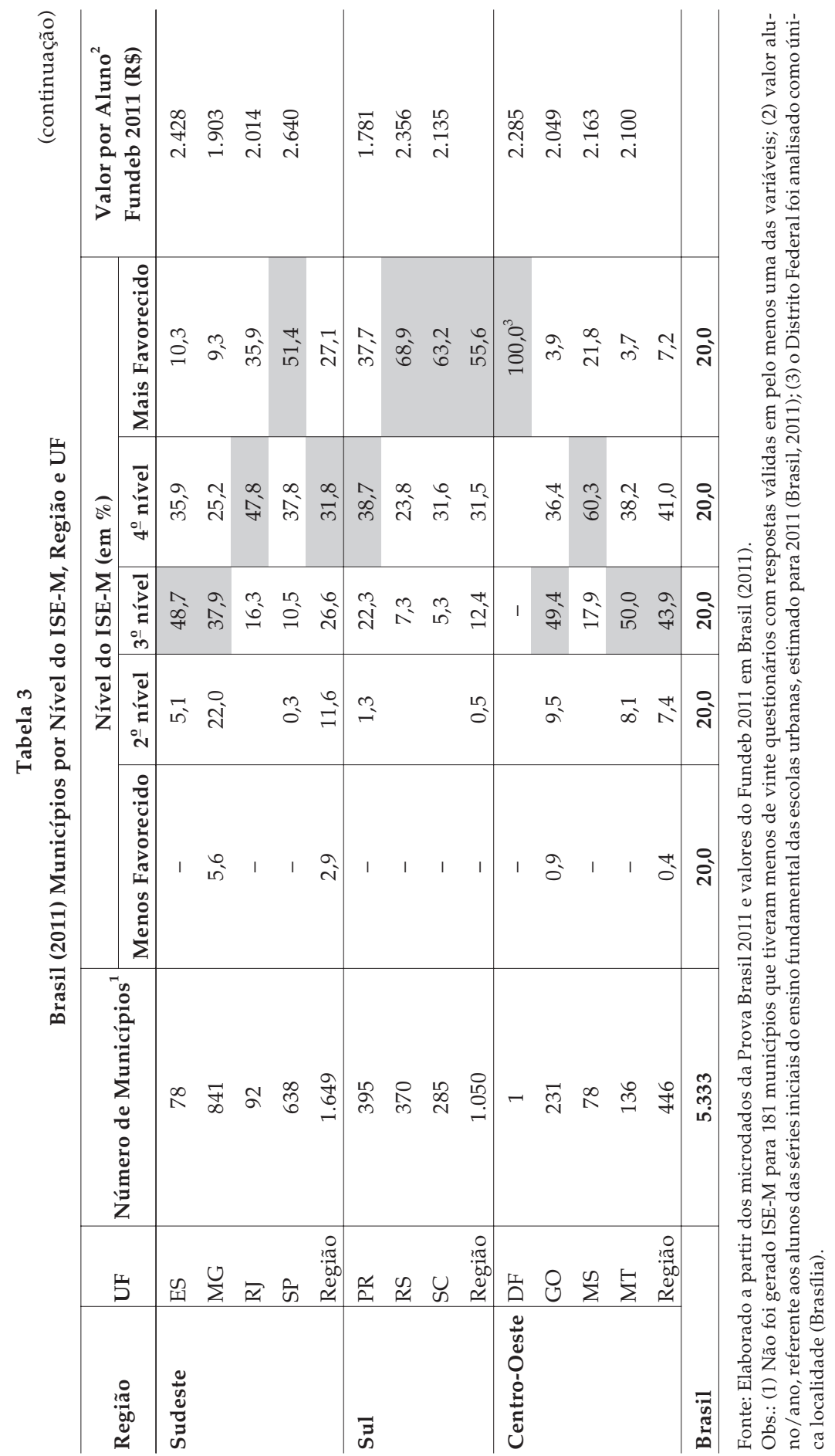

150 DADOS - Revista de Ciências Sociais, Rio de Janeiro, vol. 57, no 1, 2014 
segundo aquele levantamento, com o valor médio de US\$pp 2.571 , investe menos do que países vizinhos como o Chile e a Argentina que gastam, respectivamente, US\$pp 3.110 e US\$ $\$_{p p p} 3.930$ por aluno ao $a^{27}$ (OCDE, 2013). Estes dados são importantes para destacar que os países que atualmente possuem um sistema educacional mais inclusivo e com qualidade reconhecida, que já superaram o desafio de matricular todas as crianças e jovens em idade escolar e dotar todas as escolas com itens de infraestrutura educacional elementar para um ensino de qualidade (como biblioteca, laboratório de ciências e de informática, acesso à internet e quadra de esportes, além de todos os professores com pelo menos formação em nível superior), tarefa que o Brasil ainda tem longo caminho para concluir, investem mais em Educação Básica (Alves e Passador, 2011; Pinto e Alves, 2011).

Considerando os valores estimados para o Brasil em 2011, que variam entre R\$1.72928 (praticados por dez estados: AM, PA, AL, BA, CE, MA, PB, PE, PI e RN) e R \$ 2.915 (praticado em Roraima), verifica-se que não há relação entre o nível socioeconômico da população escolar e os valores praticados nos estados, e que, dessa forma, as diferenças na capacidade de investimento (que é de 53\%, por exemplo, entre o estado mais rico da federação, São Paulo, e os dez estados que praticam os menores valores do fundo) podem atuar como reforçador das desigualdades educacionais regionais.

Neste sentido, nota-se que, no Nordeste, onde há maior proporção de municípios com baixo nível socioeconômico, oito estados praticam o valor mínimo nacional do Fundeb. No Norte, destaca-se o caso de Roraima que, na condição de ex-território, consegue auferir boa arrecadação tributária para um número proporcionalmente menor de alunos, o que lhe dá a condição de maior valor per capita nacional. Na região Centro-Oeste, a ordem de valores do fundo e do nível socioeconômico dos municípios nos estados é diametralmente inversa ao que sugeriria uma política de financiamento baseada na equidade. O descompasso entre posição socioeconômica dos municípios e valor do Fundeb também é verificado no Sul e no Sudeste, quando analisados separadamente. Este cenário mostra que a política de financiamento educacional não consegue equalizar as diferenças do potencial de arrecadação tributárias impostas pelas peculiaridades econômicas dos estados e pela configuração do federalismo fiscal brasileiro para garantir igualdade no financiamento da oferta do direito à educação ${ }^{29}$.

Isso tem se traduzido em estratificação das oportunidades e resultados educacionais entre os estados brasileiros (com desvantagem para as lo- 
calidades em que vive maior proporção da população mais pobre), sobretudo nos aspectos objetivos que podem ser aperfeiçoados por meio de maior investimento financeiro do Estado (infraestrutura das escolas, materiais didáticos, salários e formação dos profissionais da educação), como mostram Alves, Gouveia e Viana (2012) e Alves e Silva (2013).

O mapa apresentado na Figura 1 mostra a distribuição dos municípios no território nacional e localiza espacialmente as informações da Tabela 3.

Figura 1

Nível Socioeconômico dos Alunos das Escolas Públicas nos Municípios Brasileiros Brasil (2011)

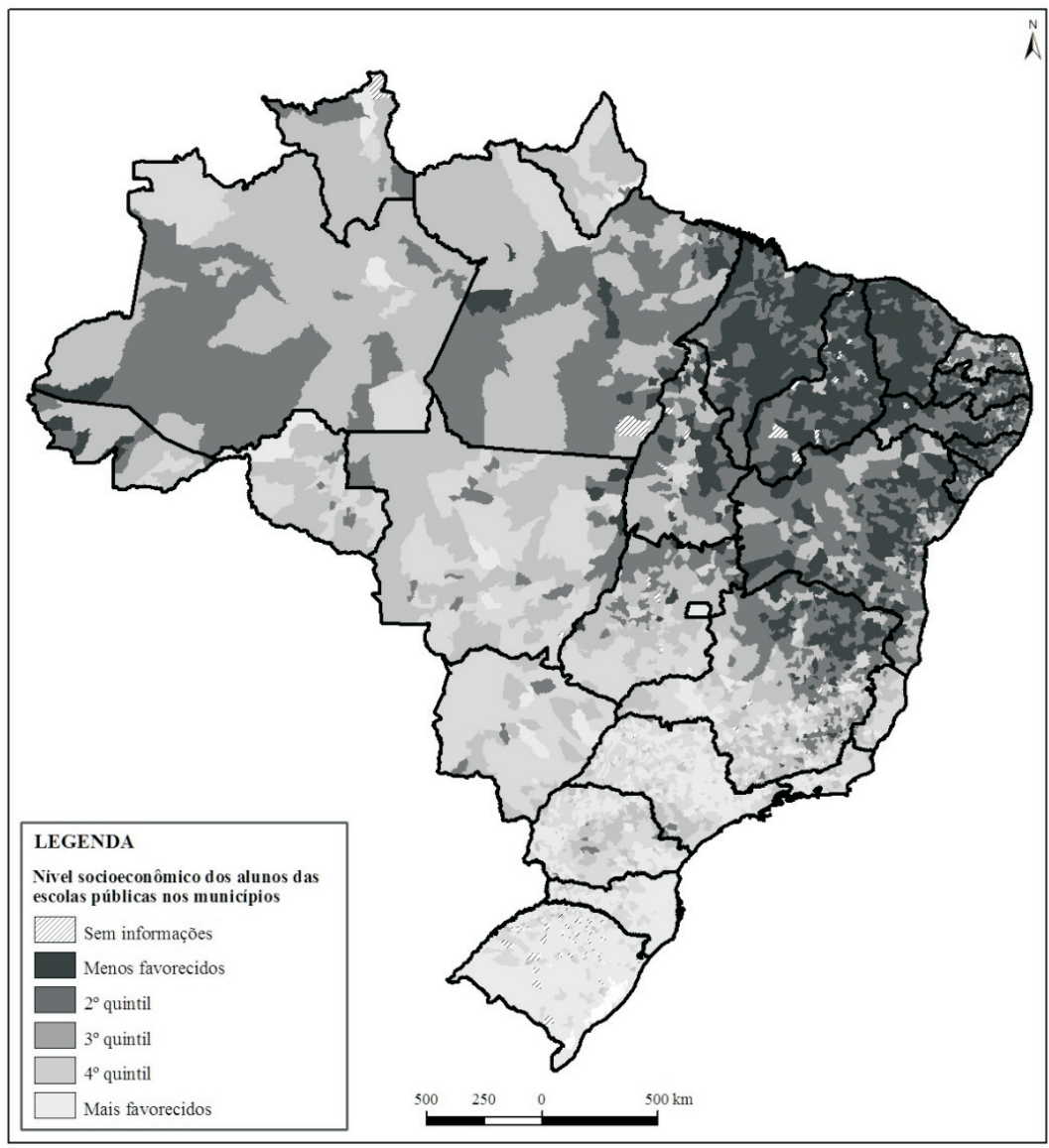

Fonte: Elaborado a partir dos microdados da Prova Brasil 2011. 
Proposta de um Indicador Socioeconômico...

\section{CONSIDERAÇÕES FINAIS}

A proposta de indicador apresentada neste artigo partiu das evidências acumuladas em pesquisas de que o nível socioeconômico dos alunos é um fator relevante para explicar as diferenças do desempenho escolar e, consequentemente, da apropriação dos resultados educacionais pelos diferentes grupos sociais. Partiu também do pressuposto de que é tarefa do Estado amenizar, por meio de ações equalizadoras, os efeitos indesejados da pobreza no desempenho das crianças e jovens que chegam às escolas públicas em desvantagem.

O indicador descreveu o contexto econômico das famílias e a escolaridade dos pais de quase três milhões de alunos agregados em $5.333 \mathrm{mu}$ nicípios. Os resultados mostraram que há associação positiva entre o status socioeconômico dos alunos e as regiões do país. Também foi evidenciada a ineficácia do modelo de financiamento praticado pela política de fundos para corrigir o descompasso entre nível socioeconômico dos alunos das diferentes regiões e a capacidade de investimento em educação no contexto dos estados no atual quadro do federalismo fiscal brasileiro, sem contar com maior participação dos recursos da União neste nível de ensino.

Neste contexto, a construção de uma medida como o ISE-M sugere, como estratégia útil às secretarias municipais e estaduais de educação para a identificação das comunidades mais desfavorecidas no âmbito de suas redes, que estudos futuros apliquem a metodologia proposta ao nível das unidades escolares, constituindo assim um indicador socioeconômico para as escolas. Igualmente, sugere a análise da associação entre o contexto socioeconômico e o desempenho educacional dos alunos e as condições de oferta de ensino das escolas.

Por fim, considerando que, de forma ideal, num estado de direito, todos nascem, de fato, iguais perante a lei, as oportunidades educacionais devem ser oferecidas igualitariamente entre todos, pois, de outra forma, a educação passa a servir como fator mantenedor das distâncias entre as classes sociais (Buchmann e Hannum, 2001; Reardon e Robinson, 2008; Barros et al. 2001; Cury, 2008), Espera-se que o indicador proposto seja somado a outros esforços que visam instrumentalizar os órgãos gestores da educação brasileira no processo de identificação dos municípios em que estão, em maior proporção, os alunos oriundos de contextos socioeconômicos mais desfavoráveis, a fim de que políticas pú- 
blicas educacionais norteadas pelo princípio da equidade sejam direcionadas de modo eficaz.

(Recebido para publicação em setembro de 2012)

(Reapresentado em julho de 2013)

(Aprovado para publicação em fevereiro de 2014)

\section{NOTAS}

1. O direito à educação foi inserido pela primeira vez nas constituições brasileiras no texto de 1934 e só foi suprimido no período de vigência da Carta autoritária de 1937 até a outorga da Constituição de 1946. O dever da oferta pelo Estado, por sua vez, constou pela primeira vez na Constituição de 1988.

2. Apesar de a Prova Brasil ter sido realizada também em 2013, os microdados desta edição não haviam sido disponibilizados pelo Inep/MEC no período de finalização deste artigo.

3. Devido às características do federalismo brasileiro, que admite a figura dos municípios como ente federativo com estrutura político-administrativa autônoma e o regime de cooperação entre União, Estados e Municípios para oferta da educação (art. 211 da Constituição Federal), as municipalidades constituem um lócus importante para as políticas públicas educacionais. Nelas, os governos municipais atuam por meio de secretarias de educação próprias, as secretárias estaduais implementam suas estratégias por meio de unidades regionais que agregam um certo número de municípios e a União desenvolve suas ações suplementares (como, por exemplo, nos convênios realizados no âmbito do Plano de Ações Articuladas, que incentiva a elaboração de um plano educacional no âmbito dos municípios).

4. Embora tenha sido o mais influente para as pesquisas sociológicas contemporâneas, o trabalho de Duncan não foi pioneiro. Iniciativas semelhantes foram empreendidas por Chapin (1928) e Blishen (1958) em décadas anteriores.

5. Informa os aspectos econômicos da opção de moradia da família no que se refere à locação, forma de aquisição ou propriedade do imóvel. Esta variável geralmente é utilizada em pesquisas sociais como indicador de renda e riqueza da família.

6. Programa internacional de avaliação comparada organizado pela Organização para a Cooperação e Desenvolvimento Econômico (OCDE) que abrange três habilidades: leitura, matemática e ciências. O teste é aplicado a estudantes de 15 anos (idade que coincide com o final do período da escolarização básica compulsória em grande parte dos países) dos países membros da OCDE (29 países desenvolvidos e o México) e outros, como o Brasil, que participam como convidado. Na edição de 2009, o PISA contou com a participação de 66 países. 
7. A versão mais atual da ISCO foi publicada pela International Labor Organization, em 2008.

8. Os estratos ocupacionais vão de baixo-inferior (formado por trabalhadores rurais não qualificados), passando por níveis intermediários como baixo-superior, médio-inferior, médio-médio e médio-superior até alto (composto por profissionais de nível superior e grandes proprietários).

9. Estas informações fazem parte do banco de dados de uma pesquisa longitudinal realizada com mais de 20 mil alunos em mais de 300 escolas de cinco cidades brasileiras denominada Geres.

10. Esta avaliação compõe o Sistema de Avaliação da Educação Básica (Saeb) realizado pelo Inep/MEC a cada dois anos desde 1990. Este sistema foi restruturado em $2005 \mathrm{e}$, a partir daquele ano, passou a aplicar uma avaliação adicional censitária, conhecida como Prova Brasil. O objetivo desta prova é avaliar as habilidades dos estudantes em língua portuguesa e matemática por meio de testes padronizados com base na proposta do currículo nacional. Além disso, aplica questionários contextuais a alunos, professores e diretores para conhecer aspectos intervenientes do processo educacional e da qualidade do ensino: a origem socioeconômica dos alunos, as condições de trabalho dos profissionais da educação, a organização do trabalho da escola etc.

11. O questionário completo aplicado aos alunos da $4^{\mathrm{a}}$ série ( $5^{\underline{0}}$ ano) tem 54 questões, e, aos alunos da $8^{\underline{a}}$ série ( $9 \underline{0}$ ano), tem 58 questões. Ambos podem ser acessados em ftp://ftp.inep.gov.br/microdados/microdados_prova_brasil_2011.zip

12. As questões anuladas, em branco ou que os alunos declaravam não saberem a resposta foram consideradas inválidas.

13. Acredita-se que este número é razoável, uma vez que a Prova Brasil é aplicada somente em escolas públicas urbanas com pelo menos vinte alunos. Este é um dos critérios necessários adotados para possibilitar a estimação do desempenho médio ao nível de escolas e municípios.

14. Conforme Pasquale e Primi (2003:102), “a Teoria da Resposta ao Item é uma teoria do traço latente aplicada primariamente a testes de habilidade ou de desempenho. $\mathrm{O}$ termo teoria do traço latente se refere a uma família de modelos matemáticos que relaciona variáveis observáveis (itens de um teste, por exemplo) e traços hipotéticos não observáveis ou aptidões, estes responsáveis pelo aparecimento das variáveis observáveis ou, melhor, das respostas ou comportamentos emitidos pelo sujeito que são as variáveis observáveis. Assim, temos um estímulo (item) que é apresentado ao sujeito e este responde a ele. A resposta que o sujeito dá ao item depende do nível que o sujeito possui no traço latente ou aptidão.

15. O IFDM é composto por nove variáveis divididas em três fatores: emprego e renda (geração, estoque e salário médio dos empregos formais), educação (taxa de matrícula na educação infantil, taxa de abandono, taxa de distorção série-idade; percentual de docentes com formação em nível superior, média de horas de aulas diárias, resultado do Ideb) e saúde (número de consultas pré-natal, óbitos infantis por causas evitáveis, óbitos por causas mal definidas). A metodologia completa dos indicadores do Sistema Firjan está em Firjan (2010) e pode ser acessada em www.firjan.org.br.

16. Segundo o Inep/MEC, 4.286.276 alunos do $5 \underline{0}$ e $9 \stackrel{0}{0}$ ano do ensino fundamental regular de 56.222 unidades escolares urbanas e rurais que tinham, pelo menos, 20 alunos ma- 
triculados nas referidas séries foram avaliados naquele ano. Aproximadamente, 99,8\% destes alunos preencheram os questionários contextuais.

17. ftp://ftp.inep.gov.br/microdados/microdados_prova_brasil_2011.zip

18. Os questionários dos alunos do meio rural não foram utilizados, uma vez que as variáveis descritoras do contexto socioeconômico da população são próprias para o contexto urbano.

19. Não foi gerado ISE-M para 181 municípios que tiveram menos de 20 questionários com respostas válidas em pelo menos uma das variáveis.

20. A lista completa do indicador atribuído aos municípios pode ser obtida junto aos autores por meio de solicitação via correio eletrônico.

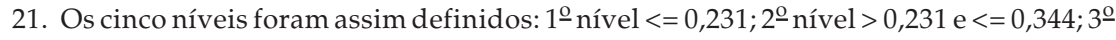
nível $>0,344$ e $<=0,507 ; 4$ oㅡvel $>0,507$ e $<=0,634$; e 5 ํㅡ nível $>0,634$.

22. É importante destacar que não foi possível identificar a formação das mães em 30,9\% dos questionários devido às respostas inválidas (26,4\% não sabiam; $3,3 \%$ deixaram em branco e 1,2\% foi anulado). O percentual é ainda maior nas respostas sobre os pais: 43,6\% dos questionários não possuíam respostas válidas (32,3\% não sabiam, $10,6 \%$ deixaram em branco e $0,7 \%$ foi anulado). Claramente, os alunos da 4 a série $/ 5^{\circ}$ o ano tiveram maior dificuldade para dar esta informação, pois foram deles $69 \%$ das respostas inválidas sobre a escolarização das mães e 61,7\% sobre os pais. Para reduzir a possibilidade de viés decorrente das respostas inválidas, no cálculo do ISE-M foram consideradas apenas as variáveis que contavam com pelo menos vinte respostas válidas em cada município.

23. O PIB per capita oferece informação sobre o potencial e o dinamismo da economia. Neste sentido, foi utilizado aqui como parâmetro para indicar, grosso modo, os municípios mais ricos e mais pobres. O PIB per capita brasileiro em 2011 era, segundo o IBGE, de R\$21.536. Os municípios com 10\% dos menores PIBs per capita tinham valores de até $R$ \$ 4.525. Os $10 \%$ maiores alcançaram valores a partir de $R$ \$ 26.252.

24. O Ideb foi criado em 2007 pelo Inep/MEC e é calculado com base no desempenho dos alunos do $5^{0}$ e 9 으 ano nos testes de português e matemática da Prova Brasil e no índice de aprovação apurado pelo Censo Escolar. Sua metodologia de cálculo pode ser acessada em http://www.inep.gov.br/download/Ideb/Nota_Tecnica_n1_concepcaoIDEB.pdf

25. A educação pública brasileira é financiada com recursos vinculados pela Constituição Federal: pelo menos $18 \%$ da receita líquida de impostos da União e $25 \%$ dos estados, distrito federal e municípios. No entanto, cada ente federativo deve atuar nas etapas que lhe cabem atuação prioritária, de acordo com o regime de colaboração: os municípios, na educação infantil e ensino fundamental; os estados, no ensino fundamental e médio; e a União, no ensino superior e de forma suplementar na educação básica. A educação básica também conta com os recursos (de menor monta) do salário-educação. O Fundeb, instituído em 2007 para substituir o Fundo de Manutenção e Desenvolvimento do Ensino Fundamental e de Valorização do Magistério (Fundef), que vigorou de 1998 a 2006, é um mecanismo de subvinculação formado por $20 \%$ dos recursos dos impostos e transferências estaduais e municipais (ICMS, FPE, FPM e IPI Exportação, ITCD, IPVA e ITR). A União acrescenta 10\% do total auferido pelos demais entes a título de complementação (Brasil, 2007).

26. O Purchasing Power Parity Dollar ou dólar com paridade de poder de compra é uma unidade monetária que torna possível a comparação de valores entre países, uma 
vez que equipara o poder de compra de alguns serviços básicos e produtos consumidos entre as nações.

27. Na publicação da OCDE (2013) consta que o Brasil investe, em média, US \$ppp 1.566 nas séries iniciais da educação básica.

28. Estes valores aplicados às séries iniciais do ensino fundamental das escolas urbanas servem como referência para os demais valores praticados no Fundeb. A lei que instituiu o fundo estabeleceu coeficientes que alteram o valor de referência de acordo com a etapa e modalidade de ensino e localidade (rural/urbana) da escola (Brasil, 2007).

29. Vale ressaltar que o Fundeb é formado no âmbito de cada estado da federação com recursos financeiros oriundos do esforço de arrecadação de seus respectivos governos estaduais e municipais. Desse modo, constitui um mecanismo eficaz para equalizar o valor por aluno investido entre os municípios de uma mesma unidade da federação, pois redistribui recursos entre as redes de ensino municipais e estaduais com base no número de matrículas. Igualmente, o fundo, como principal estratégia da política de financiamento da educação básica brasileira, por ser instituído nacionalmente por lei federal (Lei 11.494/2007 que altera o art. 60 do Ato das Disposições Constitucionais Transitórias), também traz em seu bojo a preocupação em não favorecer as disparidades no valor por aluno entre os estados. Esta intenção do legislador na concepção do fundo fica evidente no estabelecimento, em lei, de um valor mínimo nacional (abaixo do qual nenhum estado poderia ficar). Para a operacionalização deste mecanismo, ocorre a transferência de recursos do governo federal a título de complementação aos estados que não atingem o valor mínimo de referência com recursos próprios. Por isso, em sua concepção, o Fundeb tem mecanismos para também minimizar as desigualdades entre os estados da federação. Assim, para reduzir mais as desigualdades, considerando que o governo federal dispõe de maior parte da arrecadação tributária, cerca de 55,8\% em 2011, segundo a Secretaria do Tesouro Nacional (2011), bastaria que o governo federal elevasse o valor mínimo nacional do fundo e, consequentemente, elevasse a complementação ao fundo. De toda maneira, o Fundeb tem possibilitado a minimização do evidente descompasso entre capacidade de arrecadação das esferas de governo e o investimento em educação básica, uma vez que, com este fundo (a partir de 2007), a União contribui para o fundo o equivalente a $10 \%$ do investimento dos estados e municípios, a título de complemento. Antes da instituição deste fundo, o descompasso era ainda maior, pois, de acordo com Castro (2007) com base em dados do Ipea, IBGE e Inep, dos 66,6 bilhões gastos em educação básica no Brasil em 2005, os municípios investiram 49,6\%; os estados, $46,6 \%$; e a União, $4,5 \%$. 


\section{REFERÊNCIAS BIBLIOGRÁFICAS}

ALMEIDA, José Ricardo P. de. (1989), História da Instrução Pública no Brasil: 1500 a 1889. São Paulo, Inep-MEC.

ALVES, Maria Teresa G. e FRANCO, Creso. (2008), “A Pesquisa em Eficácia Escolar no Brasil: Evidências sobre o Efeito das Escolas e Fatores Associados à Eficácia Escolar", in N. Brooke e J. F. Soares (orgs.), Pesquisa em Eficácia Escolar: Origens e Trajetórias. Belo Horizonte, Editora UFMG.

ALVES, Maria Teresa G. e SOARES, José F. (2009), "Medidas de Nível Socioeconômico em Pesquisas Sociais: Uma Aplicação aos Dados de uma Pesquisa Educacional". Opinião Pública, vol. 15, no 1, pp. 1-30.

ALVES, Thiago e PASSADOR, Claudia S. (2011), Educação Pública no Brasil: Condições de Oferta, Nível Socioeconômico dos Alunos e Avaliação. São Paulo, Annablume.

ALVES, Thiago; GOUVÊA, M. Aparecida e VIANA, Adriana B. N. (2012), “O Nível Socioeconômico dos Alunos das Escolas Públicas e as Condições de Oferta de Ensino nos Municípios Brasileiros". Arquivos Analíticos de Políticas Educativas, vol. 20, no 2, pp. 1-30.

ALVES, Thiago; SILVA, Rejane M. da. (2013), “Estratificação das Oportunidades Educacionais no Brasil: Contextos e Desafios para a Oferta de Ensino em Condições de Qualidade para Todos". Educação \& Sociedade, vol. 34, no 124, pp. 851-879.

ANDRADE, Josemberg M. e LAROS, Jacob A. (2007), “Fatores Associados ao Desempenho Escolar: Estudo Multinível com Dados do Saeb /2001". Psicologia: Teoria e Pesquisa, vol. 23, no 1, pp. 33-42.

ARRETCHE, Marta. (2000), Estado Federativo e Politicas Sociais: Determinantes da Descentralização. Rio de Janeiro, Revan.

BARROS, Ricardo Paes de et al. (2001), “Determinantes do Desempenho Educacional no Brasil". Texto para Discusssão, no 834, Ipea, pp. 1-33.

BLAUG, Mark. (1992), The Methodology of Economics. 2a ed. Cambridge, Cambridge University Press.

BLISHEN, Bernard. (1958), "The Construction and Use of an Occupational Class Scale". Canadian Journal of Economics and Political Science, vol. 24, pp. 519-531.

BOBBIO, Norberto. (1992), A Era dos Direitos. Rio de Janeiro, Campus.

BOWLES, Samuel e GINTIS, Herbert. (2008), "Reforma da Escola em Retrospectiva”, in N. Brooke e J. F. Soares (orgs.), Pesquisa em Eficácia Escolar: Origens e Trajetórias. Belo Horizonte, Editora UFMG.

BRASIL. (2011), Ministério da Educação. Portaria Interministerial no 1.721, de 7 de novembro (Anexo I). Retificação da Portaria Interministerial MEC/MF n-477, de 28 de abril de 2011 e operacionalização do Fundeb no exercício de 2011: Fundo Nacional de Desenvolvimento da Educação. Disponível em: <http://www.fnde.gov.br/fnde/legislacao/portarias/item/3599-portaria-interministerial-n\%C2\%BA-1721-de-7-de-novembro-de-2011>. Acesso em: 17/3/2014. 
BRASIL. (2007), Lei no 11.494, de 20 de junho de 2007. Regulamenta o Fundo de Manutenção e Desenvolvimento da Educação Básica e de Valorização dos Profissionais da Educação - Fundeb, de que trata o art. 60 do Ato das Disposições Constitucionais Transitórias; altera a Lei no 10.195, de 14 de fevereiro de 2001; revoga dispositivos das Leis noㅗ 9.424, de 24 de dezembro de 1996, 10.880, de 9 de junho de 2004, e 10.845, de 5 de março de 2004; e dá outras providências. Disponível em: <http://www.planalto.gov.br/ccivil_03/_Ato2007-2010/2007/Lei/L11494.htm>. Acesso em: $29 / 9 / 2010$.

BUCHMANN, Claudia e HANNUM, Emily. (2001), "Education and Stratification in Developing Countries: A Review of Theories and Research". Annual Review of Sociology, no 27, pp. 77-102.

CASTRO, Jorge A. (2007), “Financiamento e Gasto Público na Educação Básica no Brasil: 1995-2005". Educação e Sociedade, vol. 28, no 100, pp. 857-876.

CHAPIN, Francis Stuart. (1928), “A Quantitative Scale for Rating the Home and Social Environment of Middle-class Families in an Urban Community: A First Approximation to the Measurement of Socioeconomic Status". Journal of Education Psychology, vol. 19, pp. 99-111.

CIRINO, Paul T. et al. (2002), "Measuring Socioeconomic Status: Reability and Preliminary Validity for Different Approaches". Assessment, vol. 9, no 2, pp. 145-155.

COLEMAN, James S. et al. (1966), Equality of Educational Opportunity. Washington, DC, US Government Pritting Office.

CURY, Carlos Roberto J. (2008), "A Educação Escolar, a Exclusão e seus Destinatários". Educação em Revista, vol. 48, pp. 205-222.

DUNCAN, Otis D. (1961), “A Socioeconomic Index for all Occupations”, in A. J. Reiss Jr. (org.) (1961), Occupations and social status. New York, Free Press, pp.139-161.

FACHEL, Jandyra M. G. (1976), Análise Fatorial. Dissertação de Mestrado em Estatística, Instituto de Matemática e Estatística. Universidade de São Paulo, São Paulo.

FIRJAN (Federação das Indústrias do Estado do Rio de Janeiro). (2010), IFDM - Índice Firjan de Desenvolvimento Municipal: Ano Base 2007. Disponível em: <http: / / www.firjan.org.br/data / pages / 2C908CE9229431C90122A3 B25FA534A2.htm>. Acesso em: 6/10/2010.

FRANCO, Creso (org.). (2001), Avaliação, Ciclos e Promoção na Educação. São Paulo, Artmed.

GANZEBOOM, Harry B. G.; GRAAF, Paul M. e TREIMAN, Donald J. (1992), “A Standard International Socio-economic index of Occupational Status". Social Science Research, vol. 21, no 1, pp. 1-56.

GANZEBOOM, Harry B. G. e TREIMAN, Donald J. (1996), “Internationally Comparable Measures of Occupational Status for the 1988 International Standard Classification of Occupations". Social Science Research, vol. 25, no 3, pp. 201-239.

HANUSHEK, Eric A. (1986), "Economics of Schooling: Production and Efficiency in Public School". Journal of Economic Literature, vol. 24, no 3, pp. 1141-1177.

(1979), "Conceptual and Empirical Issues in Estimation of Educational Production Functions". Journal of Human Resources, vol. 14, no 3, pp. 351-388. 
HASENBALG, Carlos e SILVA, Nelson do V. (2000), "Tendências da Desigualdade Educacional no Brasil". Dados, vol. 43, no 3, pp. 423-445.

HOLLINGSHEAD, August B. (1975), Four Factor Index of Social Status. Manuscrito não publicado. Yale University. Disponível em: http://www.yale.edu/sociology/faculty /docs/hollingshead_socStat4factor.pdf >. Acesso: dezembro de 2010.

INEP (Instituto Nacional de Estudos e Pesquisas Educacionais Anísio Teixeira). (2005), Pesquisa Nacional Qualidade da Educação: A Escola Pública na Opinião dos Pais: Resumo Técnico Executivo. Disponível em: <http://www.inep.gov.br/download/ imprensa/2005/censoescolar/relatório_qualidade.doc>. Acesso: fev. 2007.

JANNUZZI, Paulo de M. (2000), "Status Socioeconômico das Ocupações Brasileiras: Índices Aproximativos para 1980, 1991 e Anos de 1990". Revista Brasileira de Estatística, vol. 61, no 216, pp. 47-74.

JENCKS, Christopher et al. (1972), Inequality: A Reassessment of the Effect of Family and Schooling in America. New York, Basic Books.

LEE, Valerie E. (2000), “Using Hierarchical Linear Modeling to Study Social Contexts: The Case of School Effects". Educational Psychologist, vol. 35, no 2, pp. 125-141.

MADAUS, George F.; AIRASIAN, Peter W. e KELLAGHAN, Thomas. (2008), “Estudos Empíricos", in N. Brooke e J. F. Soares (orgs.), Pesquisa em Eficácia Escolar: Origens e Trajetórias. Belo Horizonte, Editora UFMG.

MOSTELLER, Frederick e MOYNIHAN, Daniel P. (1972), On Equality of Educational Opportunity. New York, Vintage Books.

NAKAO, Keiko e TREAS, Judith. (1992), “The 1989 Socioeconomic Index of Occupational: Construction from the 1989 Occupational Prestige Scores". General Social Survey Methodological Report, no 74, University of Chicago/National Opinion Research Center.

OCDE. (2013), Education at a Glance 2013: OECD indicators. Disponível em: <http://www.oecd-ilibrary.org/ education/education-at-a-glance-2013/indicator-b1-how-much-is-spent-per-student_eag-2013-13-en>. Acesso em: 17/3/2014.

OLIVEIRA, Romualdo P. (2007), “Da Universalização do Ensino Fundamental ao Desafio da Qualidade: Uma Análise Histórica". Educação e Sociedade, vol. 28, no 100, pp. 661-690.

OSBORN, Albert. (1987), "Assessing the Socio-Economic Status of Families". Sociology, vol. 21, no 3, pp. 429-448.

PACHECO, Regina Silvia V. M. (1999), “Administração Pública Gerencial: Desafios e Oportunidades para os Municípios Brasileiros", in Cepam-Fundação Prefeito Faria Lima (org.), O Município no Século XXI: Cenários e Perspectivas. São Paulo, Cepam.

PASQUALI, Luiz e PRIMI, Ricardo. (2003), "Fundamentos da Teoria da Resposta ao Item: TRI". Avaliação Psicológica [online], vol. 2, no 2, pp. 99-110.

PASTORE, José e SILVA, Nelson do V. (2000), Mobilidade Social no Brasil. São Paulo, Makron Books.

PEREIRA, Vinicius R. (2004), Métodos Alternativos no Critério Brasil para Construção de Indicadores Socioeconômicos: Teoria da Resposta ao Item. Dissertação de Mestra- 
do em Engenharia Elétrica, Departamento de Engenharia Elétrica, Pontifícia Universidade Católica do Rio de Janeiro, Rio de Janeiro.

PINTO, José Marcelino R. e ALVES, Thiago. (2011), “O Impacto Financeiro da Ampliação da Obrigatoriedade Escolar no Contexto do Fundeb". Educação \& Realidade, vol. 36, no 2, pp. 605-624.

PLOWDEN REPORT. (1967), Children and Their Primary Schools. London, HMSO.

REARDON, Sean F. e ROBINSON, Joseph P. (2008), "Patterns and Trends in Racial/Ethnic and Socioeconomic Academic Achievement Gaps", in H. F. Ladd e E. B. Fiske (orgs.), Handbook of Research in Education Finance and Policy. New York, Routledge, pp. 497-516.

ROTHSTEIN, Richard e JACOBSEN, Rebecca. (2008), “Educational Goals: A Public Perspective", in H. F. Ladd e E. B. Fiske (orgs.), Handbook of Research in Education Finance and Policy. New York, Routledge, pp. 78-86.

RUTTER, Michael et al. (1979), Fifteen Thousand Hours: Secondary Schools and Their Effects on Children. Cambridge, Harvard University Press.

SANTOS, José Alcides F. (2005), “Uma Classificação Socioeconômica para o Brasil”. Revista Brasileira de Ciências Sociais, vol. 20, no 58, p.27-45.

SCALON, Maria Celi. (1998). “Mapeando Estratos: Critérios para Escolha de uma Classificação". Dados, vol. 41, no 2, pp. 337-375.

SCHULTZ, Theodore William. (1973), O Capital Humano: Investimentos em Educação e Pesquisa. Rio de Janeiro, Zahar.

SECRETARIA DO TESOURO NACIONAL. (2011), Resultado Nominal do Governo Geral 2011. Brasília, STN/Cesef.

SIRIN, Selcuk R. (2005), "Socioeconomic Status and Academic Achievement: A Meta-Analytic Review of Research". Review of Educational Research, vol. 75, no 3, pp. 417-453.

SOARES, José F. (2004), “Qualidade e Equidade na Educação Básica Brasileira: A Evidência do Saeb-2001". Archivos Analíticos de Políticas Educativas, vol. 12, no38. Disponível em: <http://epaa.asu.edu.epaa/v12n38/>. Acesso em: fev. 2007.

e ALVES, Maria Teresa G. (2003), “Desigualdades Raciais no Sistema Brasileiro de Educação Básica". Educação e Pesquisa, vol. 29, no 1, p.147-165.

SOARES, José F. e ANDRADE, Renato J. (2006), "Nível Socioeconômico, Qualidade e Equidade das Escolas de Belo Horizonte". Ensaio: Avaliação e Políticas Públicas em Educação, vol.14, no 50, pp. 107-126.

SOUZA, Celina. (2005), “Sistema Brasileiro de Governança Local: Inovações Institucionais e Sustentabilidade", in C. Lubambo, D. Bandeira e M. A. Melo (orgs.), Desenho Institucional e Participação Política - Experiências do Brasil Contemporâneo. Petrópolis, Vozes.

STEVENS, Gillian e FEATHERMAN, David L. (1981), "A Revised Socioeconomic Index of Occupational Status". Social Science Research, vol.10, no 4, pp. 364-395.

STEVENSON, William J. (1986), Estatística Aplicada à Administração. São Paulo, Harbra. 
Thiago Alves, Maria Aparecida Gouvêa e Adriana Backx Noronha Viana

TEDESCO, Juan Carlos. (2002), “Prólogo”, in J. C. Tedesco (org.), Equidade e Financiamento da Educação na América Latina. Brasília, Unesco.

WHITE, Karl R. (1982), "The Relation between Socioeconomic Status and Academic Achievement". Psychological Bulletin, vol. 91, no 3, pp. 461-481.

WILLMS, J. Douglas. (1992), Monitoring School Performance: A Guide for Educators. London, Falmer. 
Proposta de um Indicador Socioeconômico...

\section{Apêndice 1}

\section{Coeficiente de Variação}

\begin{tabular}{l|c|c|c|c|c|c}
\hline Variável & N & Mínimo & Máximo & Média & $\begin{array}{c}\text { Desvio } \\
\text { padrão }\end{array}$ & $\begin{array}{c}\text { Coef. de } \\
\text { Variação }\end{array}$ \\
\hline V1 - Televisão & 5.445 & 0,23 & 0,83 & 0,51 & 0,09 & $17 \%$ \\
V2 - Rádio & 5.445 & 0,06 & 0,78 & 0,39 & 0,09 & $23 \%$ \\
V3 - Videocassete ou DVD & 5.444 & 0,35 & 1,00 & 0,85 & 0,07 & $9 \%$ \\
V4 - Geladeira & 5.447 & 0,28 & 0,73 & 0,53 & 0,04 & $8 \%$ \\
V5 - Freezer & 5.439 & 0,06 & 1,00 & 0,57 & 0,19 & $33 \%$ \\
V6 - Máquina de lavar roupa & 5.447 & 0,02 & 1,00 & 0,59 & 0,24 & $40 \%$ \\
V7 - Carro & 5.445 & - & 0,58 & 0,18 & 0,10 & $55 \%$ \\
V8 - Banheiro & 5.447 & 0,11 & 0,49 & 0,30 & 0,04 & $15 \%$ \\
V9 - Empregada doméstica & 5.446 & - & 0,20 & 0,06 & 0,02 & $39 \%$ \\
V10 - Computador & 5.446 & - & 1,00 & 0,43 & 0,20 & $47 \%$ \\
V11 - Internet & 5.446 & - & 0,90 & 0,32 & 0,17 & $52 \%$ \\
V12 - Escolaridade da mãe & 5.384 & 0,04 & 0,79 & 0,31 & 0,10 & $32 \%$ \\
V13 - Escolaridade do pai & 5.335 & - & 0,69 & 0,26 & 0,10 & $40 \%$ \\
\hline
\end{tabular}

Fonte: Resultados da análise dos microdados da Prova Brasil 2011.

\section{Apêndice 2}

\section{Matriz de Correlação}

\begin{tabular}{lccccccccc}
\hline Variável & V2 & V5 & V6 & V7 & V9 & V10 & V11 & V12 & V13 \\
\hline V2 - Rádio & $\mathbf{1 , 0 0}$ & & & & & & & & \\
V5 - Freezer & 0,65 & $\mathbf{1 , 0 0}$ & & & & & & & \\
V6 - Máquina de lavar roupa & 0,57 & 0,79 & $\mathbf{1 , 0 0}$ & & & & & & \\
V7 - Carro & 0,74 & 0,86 & 0,77 & $\mathbf{1 , 0 0}$ & & & & & \\
V9 - Empregada doméstica & $-0,10$ & $-0,09$ & 0,03 & $-0,07$ & $\mathbf{1 , 0 0}$ & & & & \\
V10 - Computador & 0,69 & 0,85 & 0,79 & 0,87 & $-0,03$ & $\mathbf{1 , 0 0}$ & & & \\
V11 - Internet & 0,64 & 0,78 & 0,72 & 0,81 & 0,00 & 0,96 & $\mathbf{1 , 0 0}$ & & \\
V12 - Escolaridade da mãe & 0,05 & 0,31 & 0,35 & 0,27 & 0,24 & 0,44 & 0,46 & $\mathbf{1 , 0 0}$ & \\
V13 - Escolaridade do pai & 0,23 & 0,46 & 0,49 & 0,41 & 0,11 & 0,60 & 0,61 & 0,78 & $\mathbf{1 , 0 0}$ \\
\hline
\end{tabular}

Fonte: Resultados da análise dos microdados da Prova Brasil 2011. 
Thiago Alves, Maria Aparecida Gouvêa e Adriana Backx Noronha Viana

\section{Apêndice 3}

\section{Resultados da Análise Fatorial}

\begin{tabular}{r|c}
\hline Estatística & Valores \\
\hline $\mathrm{KMO}^{(1)}:$ & 0,864 \\
\hline Total de Variância Explicada ${ }^{(2)}$ : & $84,93 \%$ \\
\hline Fator 1 = V2, V5, V6, V7, V10, V11: & $57,03 \%$ \\
Fator 2 = V12, V13: & $27,89 \%$ \\
\hline
\end{tabular}

Fonte: Resultados da análise dos microdados da Prova Brasil 2011.

Obs.: (1) Kaiser-Meyer-Olkin, medida que confronta as correlações totais entre pares de variáveis com as correlações residuais entre os pares; (2) soma das variâncias explicadas por todos os fatores. Fator 1: V2, V5, V6, V7, V10, V11 = 57,03\% e Fator 2: V12, V13 = 27,89\%

\begin{tabular}{l|c|c}
\hline Variável & MSA $^{(3)}$ & Comunalidade $^{(4)}$ \\
\hline V2 - Rádio &, 930 &, 746 \\
V5 - Freezer &, 932 &, 837 \\
V6 - Máquina de lavar roupa &, 942 &, 743 \\
V7 - Carro &, 911 &, 891 \\
V10 - Computador &, 809 &, 940 \\
V11 - Internet &, 827 &, 871 \\
V12 - Escolaridade da mãe &, 725 &, 893 \\
V13 - Escolaridade do pai &, 805 &, 873 \\
\hline
\end{tabular}

Fonte: Resultados da análise dos microdados da Prova Brasil 2011.

Obs.: (3) Measures of Sampling Adequacy, equivalente a medidas individuais de adequação da amostra para cada variável; (4) medida referente à soma dos quadrados das cargas fatoriais para cada variável que representa a porcentagem da variância de cada variável captada pelos fatores em conjunto.

\section{Apêndice 4}

Análise de Variância das Variáveis Dentro e Entre os Níveis do ISE-M

\begin{tabular}{l|c|c}
\hline Variável & F & Sig. \\
\hline V10 - Computador & $11.741,72$ &, 000 \\
V11 - Internet & $6.614,90$ &, 000 \\
V5 - Freezer & $5.118,35$ &, 000 \\
V7 - Carro & $5.059,24$ &, 000 \\
V6 - Máquina de lavar roupa & $3.219,56$ &, 000 \\
V2 - Rádio & $1.344,49$ &, 000 \\
V13 - Escolaridade do pai & 948,01 &, 000 \\
V12 - Escolaridade da mãe & 462,68 &, 000 \\
\hline
\end{tabular}

Fonte: Resultados da análise dos microdados da Prova Brasil 2011. 
Proposta de um Indicador Socioeconômico...

\author{
ABSTRACT \\ Proposal for a Socioeconomic Indicator for Students from Public Schools in \\ Brazilian Municipalities
}

This article aims to (a) propose an indicator to describe the socioeconomic status of primary schoolchildren in public schools in Brazilian municipalities and (b) identify the differences between localities. The analysis is relevant given the evidence of stratification of educational opportunities resulting from historical, cultural, economic, political, and social factors that have impacted educational demand by families and the supply of schooling by governments that generate disparity of appropriation of educational results between social groups in Brazil. A quantitative descriptive survey was performed using data on 3.9 million pupils from 46.290 urban public schools in 5.492 municipalities (counties) that applied the "Prova Brasil" test in 2011. The Student Socioeconomic Indicator for Municipalities (ISE-M) was calculated using factor analysis. The results allowed identifying the municipalities with the highest proportion of poor pupils, besides evaluating socioeconomic disparity between municipalities.

Key words: primary education; educational policy; socioeconomic status of students; social inequalities; educational inequalities

\title{
RÉSUMÉ
}

Proposition d'un Indicateur Socioéconomique pour les Élèves des Écoles Publiques des Municipalités Brésiliennes

Dans cet article, on cherche à: (a) proposer un indicateur capable de décrire la situation socioéconomique des élèves de primaire des écoles publiques dans les municipalités brésiliennes; et (b) faire ressortir les différences entre les localités existantes. Cette analyse se justifie face aux manifestations de stratification des opportunités educatives découlant de facteurs historico-culturels, économiques, politiques et sociaux qui ont eu un impact sur la demande des familles pour l'éducation et sur l'offre en enseignement de la part des gouvernements, source de grande disparité dans l'appropriation des résultats en éducation chez les groupes sociaux au Brésil. On a effectué une enquête quantitative descriptive à partir de données de 3,9 millions d'élèves de 46.290 écoles publiques urbaines sur 5.492 municipalités ayant réalisé la "Prova Brasil" de 2011. L'indice socioéconomique des élèves des municipalités (ISE-M) a été calculé à l'aide de l'analyse factorielle. Les résultats ont permis d'identifier les municipalités où réside le plus haut pourcentage d'élèves pauvres et d'en évaluer, entre elles, la disparité socioéconomique.

Mots-clés: éducation primaire; politique éducative; niveau socioéconomique des élèves; inégalités sociales; inégalités dans l'éducation 


\section{RESUMEN}

Propuesta de un Indicador Socioeconómico para los Alumnos de las Escuelas Públicas de los Municipios Brasileños

Este artículo tiene un doble objetivo: (a) proponer un indicador para describir la situación socioeconómica de los estudiantes en las escuelas públicas de educación básica / primaria en los municipios brasileños; y (b) poner de relieve las diferencias entre las localidades. Dicho análisis es relevante ante las evidencias de estratificación de las oportunidades educativas por factores histórico-culturales, económicos, políticos y sociales que han afectado la demanda educativa de las familias, la oferta de educación por parte de los gobiernos y que generan gran disparidad en la apropiación de los resultados educativos entre los grupos sociales en Brasil. Se realizó una investigación cuantitativa descriptiva que utilizó datos de 3,9 millones de alumnos de 46.290 escuelas públicas urbanas en 5.492 municipios que hicieron la "Prueba Brasil" de 2011. Se calculó el Indicador Socioeconómico Estudiantil de los Municipios (ISE-M) por medio del análisis factorial. Los resultados permitieron identificar los municipios con mayor proporción de alumnos más pobres y evaluar la disparidad socioeconómica entre los municipios.

Palabras clave: educación básica; política educativa, nivel socioeconómico de los alumnos; desigualdades sociales; desigualdades educativas 